\title{
Dysfunctional Adiposity Index as a Useful Clinical Tool for Early Identification of Adipose Tissue Morpho-Functional Abnormalities and Cardiometabolic Disorders in Apparently Healthy Subjects
}

Juan Reyes-Barrera

Instituto Nacional de Cardiología Ignacio Chávez: Instituto Nacional de Cardiologia Ignacio Chavez

Victor H. Sainz-Escárrega

Instituto Nacional de Cardiología Ignacio Chávez: Instituto Nacional de Cardiologia Ignacio Chavez

Aida X. Medina-Urritia

Instituto Nacional de Cardiología Ignacio Chávez: Instituto Nacional de Cardiologia Ignacio Chavez

Esteban Jorge-Galarza

Instituto Nacional de Cardiología Ignacio Chávez: Instituto Nacional de Cardiologia Ignacio Chavez

Horacio Osorio-Alonso

Instituto Nacional de Cardiología Ignacio Chávez: Instituto Nacional de Cardiologia Ignacio Chavez

Margarita Torres-Tamayo

Instituto Nacional de Cardiología Ignacio Chávez: Instituto Nacional de Cardiologia Ignacio Chavez

Gabriela Leal-Escobar

Instituto Nacional de Cardiología Ignacio Chávez: Instituto Nacional de Cardiologia Ignacio Chavez

Carlos Posadas-Romero

Instituto Nacional de Cardiología Ignacio Chávez: Instituto Nacional de Cardiologia Ignacio Chavez

Ivan Torre-Villalvazo

Instituto Nacional de Ciencias Médicas y Nutrición Salvador Zubiran: Instituto Nacional de Ciencias Medicas y Nutricion Salvador Zubiran

Juan Gabriel Juárez-Rojas ( $\nabla$ gaboyk2@gmail.com )

Instituto Nacional de Cardiologia Ignacio Chavez https://orcid.org/0000-0001-8864-2304

Original investigation

Keywords: Adipose tissue, Dysfunctional adiposity index, Cardiometabolic

Posted Date: November 3rd, 2020 
License: (c) (i) This work is licensed under a Creative Commons Attribution 4.0 International License. Read Full License 


\section{Abstract}

\section{Background}

Compared to body mass index (BMI), waist circumference (WC), and adiposity measurements, adipose tissue morpho-functionality evaluations are more consistent predictors of cardiometabolic abnormalities. However, these evaluations require determination of adipokines and other non-routine biochemical parameters, which is not feasible in clinical practice. The present study establishes dysfunctional adiposity index (DAI) as a simple, accessible, and reliable marker of early adipocytes morpho-functional abnormalities and cardiometabolic diseases.

Methods

To establish the DAl constant parameters, 340 subjects (134 males and 206 females) without cardiovascular risk factors were selected from a cross-sectional study. Then, DAI was calculated in 36 healthy subjects who underwent subcutaneous adipose tissue biopsy, for whom adipocytes number and size, body composition, circulating adipokines, glucose, insulin, and lipids were also determined. The correlation of DAI with adipocyte morphology (size/number of adipocytes) and functionality (adiponectin/leptin ratio) was analyzed. The receiver operating characteristic curve was used to define the optimal DAI cut-off point to identify metabolic abnormalities. Finally, the independent association of DAI with cardiometabolic abnormalities was determined in 1418 subjects from the cross-sectional study through multivariate analyses.

\section{Results}

The constant parameters to calculate the DAl were $\left[\mathrm{WC} /\left[22.79+\left[2.68^{*} \mathrm{BMI}\right]\right]\right] *[$ triglycerides $(\mathrm{TG}$, $\mathrm{mmol} / \mathrm{L}) / 1.37] *[1.19 / \mathrm{high}$ density lipoprotein-cholesterol (HDL-C, mmol/L)] for males, and [WC/[24.02+ [2.37*BMI]]]*[TG $(\mathrm{mmol} / \mathrm{L}) / 1.32] *[1.43 / \mathrm{HDL}-\mathrm{C}(\mathrm{mmol} / \mathrm{L})]$ for females. In subjects underwent biopsy, DAI correlated with adipocytes mean area $(r=0.358 ; p=0.032)$, adipocyte number $(r=-0.381 ; p=0.024)$, adiponectin/leptin ratio $(r=-0.483 ; p=0.003)$, and systemic inflammation markers. Compared to BMI, WC, and visceral fat, DAl was the only determination associated with insulin resistance (area under the curve: $0.743 ; p=0.017)$. In the cross-sectional study, $\mathrm{DAl} \geq 1.065$ was independently associated with diabetes (OR: 1.96; 95\% Cl: 1.36-2.84), non-alcoholic fatty liver disease (OR: $2.57 ; 95 \% \mathrm{Cl}: 1.98-3.33$ ), subclinical atherosclerosis (OR: 1.74; 95\%Cl: 1.02-2.94), and hypertension (OR: 1.44; 95\% Cl: 1.10-1.88).

\section{Conclusions}

The present study establishes the constant parameters to calculate the DAI and highlights that a DAI $\geq$ 1.065 is associated with early cardiometabolic abnormalities independently of adiposity and other risk factors. Since DAl is calculated using accessible parameters routinely used in the clinic, this indicator can be easily incorporated in clinical practice for the early identification of adipose tissue abnormalities in apparently healthy subjects. 


\section{Background}

In the last decades, as a consequence of globalization there has been a transition towards urbanization and increased technological reach leading to adverse and uncontrolled changes in diet and physical activity.[1-3] Overnutrition and reduced daily physical activity have greatly increased the prevalence of excess body weight worldwide.[4, 5] This situation has become a global emergency due to its association with a higher risk of general mortality, $[5,6]$ since it favors the development of cardiometabolic diseases such as non-alcoholic fatty liver disease, hypertension, diabetes, and coronary artery disease.[2, 6, 7]

Body mass index (BMI) is the most widely used indicator of excess body weight in the clinical practice. However, several authors have questioned the validity of BMI and proposed that adiposity measurements can be a more accurate predictor of metabolic health.[8, 9] Although adiposity can be evaluated with the use of multiple tools ranging from anthropometric measurements to advanced imaging techniques,[10, 11] data reported during the last 20 years have highlighted that compared to adiposity measurements, the evaluation of the morpho-functionality of adipose tissue (AT) could be more useful to estimate the risk of developing metabolic abnormalities.[12-14]

Adipose tissue dysfunction is a multi-step process where in early stages subcutaneous adipose tissue (SAT) fail to appropriately store energy, resulting in enlarged adipocytes (hypertrophic) that promotes systemic low-grade inflammation and fat deposition in visceral adipose tissue (VAT).[15] At later stages hypoxia, adipocyte pyrpoptosis, and inflammatory macrophage recruitment increases subcutaneous and visceral AT dysfunction that lead to increases ectopic fat deposition in liver and skeletal muscle, as well as to lipotoxicity, insulin resistance and impaired systemic metabolism.[16, 17] Considering that $10-40 \%$ of subjects with normal body weight have been identified with metabolic abnormalities, and $20-30 \%$ of those with $\mathrm{BMI} \geq 25 \mathrm{~kg} / \mathrm{m}^{2}$ appear to be metabolically healthy, several clinical markers have been proposed as subrogated to AT functionality in order to easily identifying cardiometabolic abnormalities. $[18,19]$

Adipocytes synthesizes and release several hormones and cytokines, named adipokines with metabolic and immunomodulatory activities. The adipokines adiponectin and leptin stimulates glucose and fatty acid uptake and oxidation, modulates macrophage and other immune cells activities, and prevents excessive body weight gain.[20,21] It has been proposed that a low adiponectin/leptin ratio (ALR) can be considered as a marker of adipose tissue dysfunction characterized by lower secretion of adiponectin in relation to leptin levels, AT hypoxia, proinflammatory macrophage polarization, altered adipokine profile, and insulin resistance. [22] On the other hand, Amato et al.[23] developed the visceral adiposity index (VAl), which involves adiposity measurements (BMI and waist circumference [WC]) and biochemical parameters associated with adipose tissue function (triglycerides [TG] and high-density lipoprotein cholesterol [HDL-C]), in order to provide more reliable information about AT functionality. Although VAl has been suggested as a marker of visceral AT function, [24] this index has been inconsistently associated with the presence of cardiometabolic abnormalities, probably due to the inclusion of subjects with different ethnicitv or with limitina clinical characteristics to the proper use of VAI. [24] This is confirmed by Loading [MathJax]/jax/output/CommonHTML/jax.js 
two previous studies carried out in the Asian population, where the VAl equation was adapted to the clinical characteristics of the subjects. The authors report that the modified VAI was significantly associated with metabolic abnormalities. $[25,26]$

Nowadays there are not consistent findings of the usefulness of VAl as a clinical marker of metabolic damage and neither study has investigated the morpho-functionality of adipose tissue of subjects with different VAI. Thus, the aims of the present study were: 1) adapt the VAl for a Hispanic population, 2) establish the adapted index as Dysfunctional Adiposity Index (DAl), based on the analysis of its relationship with adipose tissue morpho-functional characteristics, 3 ) define a cut-off point for DAI based on metabolic abnormalities, and 4) evaluate the usefulness of this DAl cut-off point as a marker of cardiometabolic abnormalities, in subjects with no evident cardiovascular disease.

\section{Methods}

Study population

The present study had two phases. The first phase was aimed to adapt VAl to DAl and evaluate its association with cardiometabolic diseases. For that purpose, we selected healthy subjects without cardiovascular risk factors from the Genetics of Atherosclerotic Disease study (GEA Spanish acronym). The GEA study was designed at the National Institute of Cardiology Ignacio Chávez, to examine the genomic basis of coronary heart disease (CHD) and to evaluate its relation with traditional and emerging cardiovascular risk factors in an adult Mexican population. The sample included 1200 patients with established premature CHD, and a control group of 1600 subjects aged 35 to 70 years, with no clinical or family history of coronary arterial disease, selected from the blood donors attending blood bank of the National Institute of Cardiology, or recruited by advertisements posted in social service centers from June 2008 through November 2012.[27] Participants of the GEA study were extensively characterized, including imaging studies, biochemical measurements, anthropometry, medical history, and sociodemographic and nutritional information collected through validated questionnaires.[28] With the purpose to estimates the constant values needed for the DAl equation, a subgroup of 340 healthy subjects without diabetes and with glucose $<5.6 \mathrm{mmol} / \mathrm{L}$, systolic/diastolic blood pressure $<140 / 90 \mathrm{mmHg}, \mathrm{TG}<1.69 \mathrm{mmol} / \mathrm{L}, \mathrm{HDL}-\mathrm{C} \geq$ $1.03 / 1.29 \mathrm{mmol} / \mathrm{L}$ for men/women, and $\mathrm{BMl}<30 \mathrm{~kg} / \mathrm{m}^{2}$, was selected from the control GEA participants. Additionally, 1418 subjects from the control group of the GEA study were used to estimate the prevalence of cardiometabolic abnormalities and its association with DAl, excluding those participants with TG > $3.15 \mathrm{mmol} / \mathrm{L}$ or $\mathrm{BMl}>40 \mathrm{~kg} / \mathrm{m}^{2}$ that are potential confounders of the original visceral adiposity index (Fig. 1a). [24] In the second phase of the present study we analyzed subcutaneous adipose tissue biopsies and evaluated body composition and circulating adipokines and cytokines in a sample of healthy subjects, to validate the usefulness of DAl as a marker of the morpho-functional state of the adipose tissue. Briefly, 350 healthy individuals without cardiovascular disease, dyslipidemia (TG > $3.15 \mathrm{mmol} / \mathrm{L}$ ), infection disease, diabetes, cancer, or any autoimmune disease, were invited through phone calls and personal interviews (from February 2018 to May 2019), to participate in the study to 
voluntarily accepted to participate in the study and were enrolled, but only 36 participants were included in the analyses due to incomplete subcutaneous adipose tissue biopsy, biochemical measurements, anthropometry, and clinical information from some participants (Fig. 1b). Both studies were approved by the research and bioethics committee of the National Institute of Cardiology and were performed following the guidelines of the Helsinki Declaration. All participants voluntarily signed the institutional informed consent form.

Clinical and anthropometrical evaluation

Participants in both studies were interviewed by a trained research staff and completed questionnaires detailing medical history, demographic characteristics, CHD history, medication, alcohol, and tobacco use. Height, weight, and waist circumference were measured; BMI was estimated based on weight $(\mathrm{kg})$ divided by height $\left(\mathrm{m}^{2}\right)$. Waist circumference was measured at the midpoint between the top of the iliac crest and the lower margin of the last palpable rib in the midaxillary line, with the patient in the standing position. After a 10 minutes rest period, blood pressure was measured three times; the average of the second and third blood pressure measurements was used for the analysis.

Biochemical measurements

In both studies, blood samples were obtained from an antecubital vein of each patient after a 12 hours overnight fast and 20 minutes in a sitting position. Plasma glucose, total cholesterol, TG, and HDL-C were measured using standardized procedures (Roche Diagnostics $\mathrm{GmbH}$, Mannheim, Germany). Low density lipoprotein cholesterol was estimated by using the De Long et al. formula.[29] Accuracy and precision of lipid measurements in our laboratory are under periodic surveillance by the Center for Disease Control and Prevention service (Atlanta, GA, USA). Inter-assay coefficients of variation were $<6 \%$ for all these assays. High-sensitivity C-reactive protein (hs-CRP) was determined by immunonephelometry on a BN Pro Spec nephelometer (Dade Behring, Marburg, Hesse, Germany), according to the manufacturer's method, with intra- and inter-assay variation coefficients below $3 \%$. Adiponectin, leptin, interleukin 6 (IL-6), interleukin $1 \beta$ (IL-1ß), monocyte chemoattractant protein-1 (MCP-1), plasminogen activator inhibitor-1 (PAl-1), and insulin were quantified using a Bio-Plex system (Bio-Rad Inc, Hercules, CA, USA), with intra- and interassay variation coefficients below $4 \%$ and $5 \%$ (respectively), for all these assays. Adiponectin/leptin ratio was calculated as indicator of adipose tissue functionality. [22,30] The homeostatic model assessment of insulin resistance (HOMA-IR) index was calculated using the formula: HOMA-IR = (Glucose $[\mathrm{mmol} / \mathrm{I}] \times$ Insulin $[\mu \mathrm{IU} / \mathrm{I}])$ / (22.5).

Computed tomography (CT)

Participants in the control group from the GEA study underwent CT to determine the presence of fatty liver or arterial calcium score $>100$ Agatston units as a subrogated of subclinical atherosclerosis. CT is a validated method for measuring coronary artery calcium [31] and non-alcoholic fatty liver disease.[32] CT of the chest was performed using a 64- channel multi-detector helical computed tomography system 
read to determine coronary artery calcification scores using the Agatston method. [31] To determine the liver and spleen attenuation, a single slice CT scan was obtained at the level of T11-T12 or T12-L1. [32]

\section{Electrical bioimpedance}

Body composition was determined in participants of the second phase of the study, using a 6-frequency electrical bioimpedance analyzer (InBodyS10, Korea), in the supine position. Total body fat percentage and visceral fat area $\left(\mathrm{cm}^{2}\right)$ were obtained. All study participants were asked to adhere to a fast of at least 4 hours before measurement and to have no metal or electronic equipment with them during the test.

Cardiometabolic abnormalities definition

In all subjects, diabetes was defined as glucose $>7.0 \mathrm{mmol} / \mathrm{L}$, hypoglycemic treatment or previous diagnosis, [33] non-alcoholic fatty liver disease as spleen-liver attenuation ratio < 1.0, [32] hypertension as self-reported treatment with antihypertensive medications or systolic/diastolic blood pressure $\geq$ $140 / 90 \mathrm{mmHg}$ [34] and subclinical atherosclerosis as coronary artery calcium > 100 Agatston units. [31]

Adipose tissue biopsies

In the 68 healthy volunteers enrolled in the study of the morpho-functionality of adipose tissue, a subcutaneous white adipose tissue sample was obtained from periumbilical fat, with surgical technique under local anesthesia (2\% lidocaine), and after an overnight fast.[35] Biopsies were immediately rinsed with sterile saline and visible blood vessels were removed with sterile tweezers. Adipose tissue biopsies were fractionated in three pieces. Two pieces were stored in cryotubes and immediately frozen in liquid nitrogen. The last piece was immediately fixed in PBS-buffered $4 \%$ paraformaldehyde for histological analyses.

Analysis of the number of adipocytes per field and adipocytes mean area

After 24 hours, fixed tissues were dehydrated in ethanol, cleared in xylene, embedded in paraffin, sectioned at $4 \mu \mathrm{m}$, and stained with hematoxylin and eosin. Digital images were obtained using a digital camera (Leica ICC50 HD) coupled to Leica DM750 microscope using a 20X lens at a resolution of $2048 \times 1536$ pixels using LAS EX V 3.0 software (Leica Microsystems, Heerbrugg Switzerland). Five fields of view image captures were taken per slide in varying parts of the fat biopsies of each patient. Adipocytes size was measured by converting pixels into microns utilizing Adiposoft (Image $J$ ) software with the following parameters: minimum diameter $10 \mu \mathrm{m}$, maximum diameter $1000 \mu \mathrm{m}$ and microns per pixel 0.439 as previously described. [36] The mean adipocytes area $\left(\mu \mathrm{m}^{2}\right)$ and number of adipocytes (per field) were determined in a blinded manner by taking into account all the adipocytes of the 5 fields of each patient. After completing the automated analyzes of the counting and area adipocytes measurements, each value in the data table was checked manually to ensure that it represented a single adipocyte in order to prevent errors that may occur during automated analyzes. 
The original formula of VAl is separately calculated in men or women and includes two sections.[23] The first section represents the proportion of central adipose tissue through waist circumference with respect to $\mathrm{BMI}$ as a measure of generalized fat. With the analysis of the linear regression between both adiposity markers, the constants of the intercepts and the slopes can be determined, which are included in the formula: WC/ [constant intercept + (slope constant $* \mathrm{BMI}$ )]. The second section represents AT function through TG and HDL-C plasma concentration assessment. In this case, median values of $T G(\mathrm{mmol} / \mathrm{L})$ and HDL-C (mmol/L) from healthy subjects without cardiometabolic risk factors are used as a reference. Thus, the final equation for DAl estimation by gender is represented as:

$\mathrm{DAI}=\left(\frac{\mathrm{WC}}{\text { constant intercept }+(\text { constant slope } * \text { BMI })}\right)\left(\frac{\mathrm{TG}}{\begin{array}{c}\text { TG median } \\ \text { reference }\end{array}}\right)\left(\frac{\begin{array}{c}\text { HDL-C median } \\ \text { reference }\end{array}}{\text { HDL-C }}\right)$

Statistical Analyses

Data are presented as means \pm standard deviation, median (interquartile range), and the number of subjects (percentages). In participants of the morpho-functionality adipose tissue study, HOMA-IR was calculated and subjects were stratified according to those below or above the median HOMA-IR value. A comparison of these groups was accomplished with Student's t, Mann-Whitney U, or Chi-square tests; respectively. Spearman coefficient correlation was calculated to evaluate the relationship of DAI with inflammatory and morpho-functional characteristics of adipose tissue. The discriminative power of the DAl and other adiposity measurements, to identify subjects with HOMA-IR above the median, was tested by calculation of the area under the receiver operating characteristic (ROC) curve (area under the curve [AUC]); the optimal cut-off point was determined by the maximal Youden index. In order to investigate the association of high DAl values with cardiometabolic abnormalities in the control group of the GEA study, a multiple logistic regression stepwise forward analysis was performed adjusting by potential confounders. The values of regression analysis are shown as odds ratio ( $95 \%$ interval of confidence). All $p$ values $<0.05$ were considered statistically significant. The statistical analyses were performed using 15.0 software SPSS (Chicago, IL, USA) and SAS JMP ® Trial version 15.1.0 (Cary, NC, USA).

\section{Results}

The control group of the GEA study included 1600 participants without coronary artery disease $(50.8 \%$ women), with a mean age of $53 \pm 9$ years, and BMl of $28.4 \pm 4.3 \mathrm{Kg} / \mathrm{m}^{2}$. To estimate the DAl, the intercept and slope constants of the VAl formula were recalculated in a subsample of 340 subjects (134 males and 206 females) without cardiovascular risk factors of the GEA study. The mean age of this subsample was $52 \pm 10$ years, $\mathrm{BMI}=25.1 \pm 2.5 \mathrm{Kg} / \mathrm{m}^{2}, \mathrm{WC}=85.8 \pm 8.5 \mathrm{~cm}, \mathrm{TG}=1.15(0.92-1.4) \mathrm{mmol} / \mathrm{L}$, and HDL-C $=$ $1.47(1.34-1.70) \mathrm{mmol} / \mathrm{L}$. The linear relationship between WC and BMI shows a significant positive males $\left(R^{2}=0.667, p<0.001\right.$; linear equation: $W C=22.79+$ 
2.68*BMI) and females $\left(R^{2}=0.584, p<0.001\right.$; linear equation: $\left.W C=24.02+2.37 * B M I\right)$. Median values of TG and HDL-C were also calculated in men $(1.37 \mathrm{mmol} / \mathrm{L}$ and $1.19 \mathrm{mmol} / \mathrm{L})$ and women $(1.32 \mathrm{mmol} / \mathrm{L}$ and $1.43 \mathrm{mmol} / \mathrm{L})$. These parameters were used to estimate DAl as following:

$$
\text { DAl male }=\left(\frac{\text { WC }}{22.79+\left(2.68^{*} \mathrm{BMI}\right)}\right)\left(\frac{\mathrm{TG}}{1.37}\right)\left(\frac{1.19}{\mathrm{HDL}-\mathrm{C}}\right)
$$

$$
\text { DAl female }=\left(\frac{\mathrm{WC}}{24.02+\left(2.37^{*} \mathrm{BMI}\right)}\right)\left(\frac{\mathrm{TG}}{1.32}\right)\left(\frac{1.43}{\mathrm{HDL}-\mathrm{C}}\right)
$$

The study of the functionality of adipose tissue includes 36 healthy individuals ( $72 \%$ women), average age of $57 \pm 9$ years, and a BMI of $26 \pm 4 \mathrm{~kg} / \mathrm{m}^{2}$. Additional file 1: Table S1 shows the clinical and biochemical characteristics of these subjects stratified according to the HOMA-IR median value (2.09). When components of the DAl were compared, we did not find statistical differences for BMI, WC, and HDLC; however, TG were significantly higher among those subjects with higher values of HOMA-IR. No differences were found between groups regarding age, percentage of total fat mass, visceral fat area, glucose, total cholesterol, low-density lipoprotein cholesterol, diastolic and systolic blood pressure, or tobacco use. The systemic inflammation markers and morpho-functional characteristics of the adipose tissue are showed in additional file 1: Table S2. Compared with subjects with HOMA-IR $<2.09$, those with higher HOMA-IR values were characterized to have a trend toward higher hs-CRP $(+128.3 \%)$, IL-1ם (+55.1\%), IL-6 (+27.6\%), MCP-1 (+8.0\%), and PAI-1 (+7.2\%) values; however, statistical difference was found only in hs-CRP serum levels. Subjects with high HOMA-IR also showed higher circulating leptin levels $(+134.6 \%)$, and although they only showed a trend towards lowest levels of adiponectin $(-12.1 \%)$, it was observed that the ALR was significantly lowest (-56.1\%) than subjects with HOMA-IR below the median. The morphological evaluation of the adipose tissue showed that subjects with high HOMA-IR values presented $44.7 \%$ bigger adipocytes mean area and $25.9 \%$ fewer adipocytes per field, which denotes hypertrophic adipocytes that were confirmed by an $84.3 \%$ higher ratio of area/number of adipocytes. In addition, the DAl also showed significantly higher values (+107.9\%) among subjects with HOMA-IR above the median.

With the purpose to investigate the possible association of DAI with the morpho-functional characteristics of adipose tissue, a Spearman coefficient correlation was carried out in the 36 participants of the adipose tissue functionality study. The results highlighted that DAI is strongly and significantly associated with both, functional (Figure 2a) and morphological (Figure 2b) adipose tissue characteristics. Moreover, the possible relationship of DAI with systemic inflammation markers was analyzed and the results shown in Figure 3 underline the strong association of DAl with hs-CRP $(r=0.603 ; p<0.001), \mathrm{IL}-1 \mathrm{I}(\mathrm{r}=0.356 ; p=$ $0.033)$, and MCP-1 $(r=0.381 ; p=0.022)$. 
In order to establish a cut-off point of the DAI to identify subjects with metabolic abnormalities, participants in the functionality adipose tissue study were analyzed in a ROC curve model, using HOMA-IR above the median as an indicator of metabolic abnormality. The Figure 4 shows that compared to BMI (AUC: $0.621 ; p=0.235$ ), WC (AUC: $0.688 ; p=0.066$ ), and visceral fat (AUC: $0.678 ; p=0.081$ ) the area under the curve of DAI was the only one significantly associated with elevated HOMA-IR (AUC: $0.743 ; p=$ 0.017). Additionally, according to the Youden index, we found that a DAl value higher than 1.065 could be useful to identify subjects with metabolic abnormalities with a sensitivity of $81 \%$ and specificity of $65 \%$.

To assess the usefulness of the DAI cut-off point in identifying the presence of cardiometabolic abnormalities, we calculated the prevalence of diabetes (12\%), non-alcoholic fatty liver disease (32\%), subclinical atherosclerosis (27\%), and hypertension (24\%) in subjects without history of coronary artery disease of the GEA study (Table 1). As shown in Figure 5, the logistic regression analysis indicates that DAI values greater than 1.065 were significantly associated with higher probability of presenting diabetes $(+96 \%)$, non-alcoholic fatty liver disease $(+157 \%)$, subclinical atherosclerosis $(+74 \%)$, and hypertension $(+44 \%)$; even after adjusting for well-established cardiovascular risk factors.

\section{Table 1. Clinical and biochemical characteristics of subjects $(n=1418)$ without history of coronary arterial disease.}

\begin{tabular}{|ll|}
\hline Females, $\mathrm{n}(\%)$ & $744(52 \%)$ \\
\hline Age (years) & $54 \pm 9$ \\
\hline Body mass index $\left(\mathrm{kg} / \mathrm{m}^{2}\right)$ & $28 \pm 4$ \\
\hline Waist circumference $(\mathrm{cm})$ & $94 \pm 11$ \\
\hline Diastolic blood pressure $(\mathrm{mmHg})$ & $72 \pm 9$ \\
\hline Systolic blood pressure $(\mathrm{mmHg})$ & $117 \pm 18$ \\
\hline Tobacco use, $\mathrm{n}(\%)$ & $312(22)$ \\
\hline Total cholesterol (mmol/L) & $4.9 \pm 0.9$ \\
\hline LDL-C (mmol/L) & $3.0 \pm 0.7$ \\
\hline HDL-C (mmol/L) & $1.2 \pm 0.3$ \\
\hline Triglycerides (mmol/L) & $1.5(1.2-2.10)$ \\
\hline Glucose (mmol/L) & $5.3 \pm 1.6$ \\
\hline Insulin $(\mu \mathrm{Ul} / \mathrm{L})$ & $16(12-22)$ \\
\hline HOMA-IR & $3.8(2.6-5.5)$ \\
\hline Dysfunctional adiposity index $\geq 1.065, \mathrm{n}(\%)$ & $896(63)$ \\
\hline
\end{tabular}


Values expressed as number (percentage), mean \pm standard deviation or median (interquartile range). LDL-C: low density lipoprotein cholesterol; HDL-C: high density lipoprotein cholesterol; HOMA-IR: homeostatic model assessment of insulin resistance.

\section{Discussion}

A perplexing by-product of contemporary human behavior characterized by overnutrition and a sedentary lifestyle is the elevated prevalence of cardiometabolic diseases as a result of positive energy balance and adipose tissue metabolic dysfunction. [7] Functional adipose tissue is able to expand through continuous pre-adipocyte recruitment and differentiation to adipocytes. However, expanding adipose tissue can become dysfunctional by alterations that reduce recruitment/differentiation capacity along with increased hypoxia and adipocyte cell death. Dysfunctional adipose tissue is directly associated with the development of insulin resistance and other cardiometabolic alterations. For that reason, the efficacy of anthropometry and other imaging techniques as markers of cardiometabolic health has been extensively debated since those measurements are unable to evaluate adipose tissue function.[10,11] The VAl has been considered as an adipose tissue functionality indicator, but its association with metabolic derangements is inconsistent.[24] These inconsistencies can arise from the application of VAl to subjects with different ethnic origin and clinical characteristics of the studied populations for which it was described. Results of the present study highlight the importance to adapt the VAl equation to the clinical characteristics of the different populations under study. Furthermore, our data allowed us to improve this equation into a generalized dysfunctional adiposity index (DAl) by analyze for the first time its association with morpho-functional adipose tissue parameters and systemic inflammation markers. The clinical usefulness of the DAI was proved at population level and shows that it was strongly and independently associated with the presence of cardiometabolic abnormalities. Altogether our results suggest that the DAI can be considered as a practical and economical tool to identify increased cardiovascular risk in otherwise apparently healthy subjects. The use of the DAI in the clinical practice could timely identify and help to prevent the development of cardiometabolic complications in persons at risk and reduce the morbi-mortality related to the dysfunction in the adipose tissue microenvironment.

A proportion of individuals with excess body weight identified through anthropometry and imaging techniques seem to have a relative protection against negative metabolic outcomes, suggesting that adipose tissue functionality rather than fat mass may be the key factor in the pathophysiology of metabolic and cardiovascular diseases.[8-14] The VAI is a simple equation used as indicator of adipose tissue functionality that includes non-invasive clinical parameters.[23] Considering that the VAI was based on Caucasian population and that parameters included in the equation have multiple discrepancies among various ethnicities, it is important to adapt the VAl according to each ethnicity. The results of the present study support that by showing that in contrast with the original VAl, the studied population shows a different pattern in the intercept and slope constants, when WC and BMI were analyzed as the expression of adipose tissue distribution. Similarly, TG and HDL-C median values were different in men and women from this Hispanic population as previously reported.[37] Moreover, in an additional analysis

Loading [MathJax]/jax/output/CommonHTML/jax.js nato et al.,[23] to estimate VAl in our population, we found 
lower and non-significant correlation of VAI with leptin $(r=0.288 ; p=0.093)$, adipocytes size $(r=0.262$; $p=0.128)$, adipocytes number $(r=-0.228 ; p=0.187), I L-1 \otimes(r=0.205 ; p=0.238)$, and MCP-1 $(r=0.323 ; p=0.059)$ as compared with the observed with the DAI (Figures 2 and 3 ). In line with this, two previous studies carried-out in Asian population adapted the VAl equation to their clinical characteristics obtaining a significant association with higher risk of cardiometabolic diseases. [25, 26]

The search of markers for adipose tissue function has led to the evaluation of numerous biochemical or morphological measurements as candidates to identify subjects at risk for metabolic abnormalities. The ALR has been proposed as an emerging biomarker of adipose tissue dysfunction that correlates with insulin resistance, metabolic abnormalities and inflammatory cytokines.[22,30] On the other hand, reduced adipocytes cell number along with enlarged size have been considered morphological indicators of hypertrophic adipocytes that play a role in obesity-related cardiovascular and metabolic abnormalities. [15-17] Data of the present study indicates that ALR significantly correlates with subcutaneous adipocytes number $(r=0.525 ; p=0.001)$ and area $(r=-0.431 ; p=0.009)$, as well as with the relation of area/number of adipocytes $(r=-0.529 ; p=0.001)$ as indicator of morphologically abnormal adipocytes. Moreover, Figure 2 shows that the simple DAl equation was strongly correlated with morpho-functional alterations in adipose tissue. The analysis of the present study also highlights that higher values of DAI directly correlates with higher systemic low-grade inflammation (Figure 3). It is important to underline that our study analyzed SAT obtained from healthy subjects, which represents the normal physiological buffer for excess energy intake. When the storage capacity of SAT is exceeded or its ability to generate new adipocytes is impaired, TG begins to accumulate in tissues outside the SAT, such as VAT, skeletal muscle, and liver.[15, 38] Thus, it can be hypothesized that in the progression of cardiometabolic alterations, the earlier stages of adipose tissue dysfunction comprise the impairment in SAT expansion and activation of inflammatory macrophages, reflected by low number of adipocytes, hypertrophy, and the presence of lowgrade systemic inflammation (MCP-1, IL-1区, and hs-CRP). The increased fatty acids release in a later stage lead to ectopic fat accumulation and progression to severe metabolic derangements in more advanced stages (Figure 6). This hypothesis is supported by previous studies showing a differential response of VAT and SAT to obesity-induced inflammation. $[14,39]$ Although VAT is considered to be prone to develop inflammation in the context of over-nutrition with respect to SAT,[39] Caputo T. et al.,[14] in an elegant animal model study, showed that after a high-fat diet intake SAT is greatly increased while VAT displays no significant differences. The authors demonstrate that at this stage SAT expansion is primarily a result of early hypertrophic adipocytes growth, whereas the proliferation of adipocyte precursors does not take place. This hypertrophic growth has been associated also with early alterations in adipose tissue adipokine secretion, characterized by low adiponectin and high leptin levels. $[15,40]$ Taken together, these data also support the concept to renamed the morpho-functional adipose tissue index as DAl, since VAI rater refers only to visceral adipose tissue which becomes dysfunctional at later stages in the process of adipose tissue derangements.

Multiple studies have reported that anthropometry and imaging techniques have shown inconsistent findings about the relationship of adiposity with cardiometabolic abnormalities.[8-11] In line with this, the Loading [MathJax]/jax/output/CommonHTML/jax.js DAl, measurements of BMI, WC, and visceral fat area were 
not significantly associated with higher HOMA-IR values. With the aim to establish a DAl cut-off point that allowed distinguish among subjects with higher cardiometabolic risk, we use the Youden formula. It is important to point out that the DAI involves gender specific constant values and it was not necessary to identify a gender specific DAl cut-off point. Additionally, it has been reported that the original VAl equation could not be apply in subjects with $\mathrm{BMI}>40 \mathrm{~kg} / \mathrm{m}^{2}$ or with $\mathrm{TG}>3.15 \mathrm{mmol} / \mathrm{L}$. [24] Considering this equation caveats our results showed that DAl values higher than 1.065 , were strongly and independently associated with the presence of cardiometabolic diseases (Figure 5). All these data suggest that the DAI may be a useful tool to identify subjects with very earlier changes in the morpho-functionality of adipose tissue that could lead to clinical manifestations.

The present study has several strengths to highlight. 1) The healthy subjects selected from the GEA study to adapt the VAl to DAl, were exhaustively characterized allowing us to calculate reliably constants for the equation, applicable to the Hispanic population. 2) Unlike other studies that includes subjects with morbid obesity or other comorbidities; participants in our study of the morpho-functionality adipose tissue had $\mathrm{BMI}$ similar to the general population $\left(\mathbb{2} 27 \mathrm{~kg} / \mathrm{m}^{2}\right)$, were apparently healthy and clinically wellcharacterized, which could reflect the early stages in the development of adipose tissue dysfunction in the general population. 3) As far as we known, the present study is the first to associate a cardiometabolic index with the morpho-functional characteristics of adipose tissue. 4) Furthermore, we evaluated the usefulness of the DAl cut-off point in a group of subjects of the GEA study that included participants with no family or personal history of clinical cardiovascular disease. On the other hand, subjects that underwent biopsy in the present study were healthy and accessing VAT could represent an unnecessary risk. Thus a potential perceived limitation of the present study is the lack of VAT samples, which would allow us to discriminate the participation of each fat depot during the early stages of adipose tissue dysfunction. Another limitation is that, we were not able to measure specific markers, gene or protein expression from the adipose tissue sample. However, several studies have demonstrated that circulating levels of adipose tissue-specific cytokines (such as adiponectin and leptin), can reflect the functional status of the adipocytes. [20,21] Finally, due to the cross-sectional nature of the present study, we were not able to determine the causality of the associations.

\section{Conclusions}

Although excess body weight and the associated non-communicable diseases have been globally and simultaneously increasing in their prevalence, adipose tissue dysfunction appear to be the key factor in the pathophysiology of obesity-related chronic metabolic and cardiovascular diseases. Nowadays there are not simple and useful clinical markers able to identify early abnormalities in adipose tissue from subjects with increased risk for developing cardiometabolic disorder although, apparently healthy. The results of the present study allowed us to establish the necessary constant parameters to calculate the DAl as a dysfunctional adipocytes index in Hispanic population. This index is based on accessible routine parameters evaluated in clinical practice and could be useful to identify early abnormalities of adipose tissue. The latter was confirmed by the finding of the association of the DAI with the morphological and Loading [MathJax]/jax/output/CommonHTML/jax.js, us adipose tissue and with the low-grade systemic 
inflammation of apparently healthy subjects. Furthermore, our results highlight that regardless of adiposity and other risk factors, DAl values greater than 1.065 could be associated with the presence of early cardiometabolic abnormalities in these apparently healthy subjects.

\section{Abbreviations}

BMI: Body mass index AT: adipose tissue; SAT: subcutaneous adipose tissue; VAT: visceral adipose tissue; ALR: adiponectin/leptin ratio; VAl: visceral adiposity index; WC: waist circumference TG: triglycerides; HDL-C: high-density lipoprotein cholesterol; DAl: dysfunctional adiposity index; GEA: the genetics of atherosclerotic disease study; CHD: coronary heart disease; LDL-C: Low density lipoprotein cholesterol; hs-CRP: high-sensitivity c-reactive protein; IL-6: interleukin 6; IL-1ß: interleukin 1 $\beta$; MCP-1: monocyte chemoattractant protein-1; PAI-1: plasminogen activator inhibitor-1; HOMA-IR: homeostatic model assessment of insulin resistance; CT: computed tomography; ROC: receiver operating characteristic; AUC: area under the curve; FFA: free fatty acids; DAMPS: damage-associated molecular patterns; OR: odds ratio; $\mathrm{Cl}$ : interval of confidence.

\section{Declarations}

\section{Acknowledgements}

The authors would like to thank Erik Alejandro Torre Anaya, Gabriela Olvera-Mayorga, and Néstor Alonso Sánchez-Ortiz, for their adipose tissue biopsies analysis support.

\section{Authors' contributions}

JRB, ITV, and JGJR raised the presented idea and designed the study. JRB, JGJR, AXMU, and EJG conducted the analyses. JRB, JGJR, VHSE, HOA, MTT, CPR, and GLE interpreted the results. JRB and JGJR developed the first draft of the manuscript. VHSE, HOA, MTT, GLE, CPR, and ITV critically reviewed the manuscript. All authors read and approved the final manuscript.

\section{Funding}

This work was partially supported by the Consejo Nacional de Ciencia y Tecnología (project numbers: SALUD-2010-2-150537 to CPR and A1-S41077 to ITV) and the Instituto Nacional de Cardiología Ignacio Chávez (project numbers: 17-1040 and 09-646).

\section{Availability of data and materials}

The datasets used and analyzed during the current study are available from the corresponding author on reasonable request.

\section{Ethics approval and consent to participate}


Both studies were approved by the research and bioethics committee of the National Institute of Cardiology and all participants voluntarily signed the institutional informed consent form.

\section{Consent for publication}

Not applicable.

\section{Competing interests}

The authors declare that there are no conflicts of interest.

\section{Author details}

1. Department of Endocrinology, Instituto Nacional de Cardiología Ignacio Chávez, Mexico City, Mexico.

2. Department of Cardiothoracic Surgery, Instituto Nacional de Cardiología Ignacio Chávez, Mexico City, Mexico.

3. Department of Cardio-Renal Physiopathology, Instituto Nacional de Cardiología Ignacio Chávez, Mexico City, Mexico.

4. Department of Nephrology, Instituto Nacional de Cardiología Ignacio Chávez, Mexico City, Mexico.

5. Department of Nutrition Physiology, Instituto Nacional de Ciencias Médicas y Nutrición Salvador Zubirán, Mexico City, Mexico.

\section{References}

1. Baker P, Machado P, Santos T, et al. Ultra-processed foods and the nutrition transition: Global, regional and national trends, food systems transformations and political economy drivers. Obes Rev. 2020;1 - 22. doi.org/10.1111/obr.13126

2. Endalifer ML, Diress G. Epidemiology, Predisposing Factors, Biomarkers, and Prevention Mechanism of Obesity: A Systematic Review. J Obes. 2020;2020:6134362. doi:10.1155/2020/6134362

3. Anekwe CV, Jarrell AR, Townsend MJ, Gaudier GI, Hiserodt JM, Stanford FC. Socioeconomics of Obesity. Curr Obes Rep. 2020;9:272-279 doi:10.1007/s13679-020-00398-7

4. Obesity and overweight.https://www.who.int/es/news-room/fact-sheets/detail/obesity-andoverweight reviewed on August 10, 2020

5. Development Initiative, Global Nutrition Report 2017: Nourishing the SDGs, Development Initiatives, Bristol, UK, 2017

6. Van DI, Kromhout D, Geleijnse JM, Boer JM, Verschuren WM: Body mass index and waist circumference predict both 10-year nonfatal and fatal cardiovascular disease risk: study conducted in 20,000 Dutch men and women aged 20-65 years. Eur J Cardiovasc Prev Rehabil. 2009;16:729-734. doi: 10.1097/HJR.0b013e328331dfc0.

7. Guilherme A, Virbasius JV, Puri V, Czech MP. Adipocyte dysfunctions linking obesity to insulin 
8. Banack HR, Wactawski-Wende J, Hovey KM, Stokes A. Is BMl a valid measure of obesity in postmenopausal women?. Menopause. 2018;25:307-313. doi:10.1097/GME.0000000000000989

9. Donini LM, Pinto A, Giusti AM, Lenzi A, Poggiogalle E. Obesity or BMI Paradox? Beneath the Tip of the Iceberg. Front Nutr. 2020;7:53. doi:10.3389/fnut.2020.00053

10. Schover, IM (2018). Metabolic consequences of adipose tissue dysfunction (Thesis for Doctor Degree). Universiteit Utrecht, Netherlands. Link: https://dspace.library.uu.nl/handle/1874/372756

11. Blundell JE, Dulloo AG, Salvador J, Fruhbeck G: Beyond BMI - phenotyping the obesities. Obes Facts. 2014;7:322-328. doi: 10.1159/000368783

12. Blüher M. Adipose tissue dysfunction contributes to obesity related metabolic diseases. Best Pract Res Clin Endocrinol Metab. 2013;27:163-177. doi:10.1016/j.beem.2013.02.005

13. Longo M, Zatterale F, Naderi J, Parrillo L, Formisano P, Raciti GA, Beguinot F, and Miele C. Adipose Tissue Dysfunction as Determinant of Obesity-Associated Metabolic Complications. Int J Mol Sci. 2019;20:2358. doi:10.3390/ijms20092358

14. Caputo T, Tran VDT, Bararpour N, et al. Anti-adipogenic signals at the onset of obesity-related inflammation in white adipose tissue. Cell Mol Life Sci. 2020;10.1007/s00018-020-03485-z. doi:10.1007/s00018-020-03485-z

15. Torre-Villalvazo I, Bunt AE, Alemán G, et al. Adiponectin synthesis and secretion by subcutaneous adipose tissue is impaired during obesity by endoplasmic reticulum stress. J Cell Biochem. 2018;119:5970-5984. doi:10.1002/jcb.26794

16. Goossens GH. The Metabolic Phenotype in Obesity: Fat Mass, Body Fat Distribution, and Adipose Tissue Function. Obes Facts. 2017;10:207-215. doi:10.1159/000471488

17. Goossens $\mathrm{GH}$. The role of adipose tissue dysfunction in the pathogenesis of obesity-related insulin resistance. Physiol Behav. 2008;94:206-218. doi: 10.1016/j.physbeh.2007.10.010

18. Wildman RP, Muntner P, Reynolds K, McGinn AP, Rajpathak S, Wylie-Rosett J, Sowers MR: The obese without cardiometabolic risk factor clustering and the normal weight with cardiometabolic risk factor clustering: prevalence and correlates of 2 phenotypes among the US population (NHANES 19992004). Arch Intern Med. 2008;168:1617-1624. doi: 10.1001/archinte.168.15.1617

19. Primeau V, Coderre L, Karelis AD, Brochu M, Lavoie ME, Messier V, Sladek R, Rabasa-Lhoret R: Characterizing the profile of obese patients who are metabolically healthy. Int J Obes. 2011;35:971981. doi: $10.1038 /$ ijo.2010.216

20. Stern JH, Rutkowski JM, Scherer PE. Adiponectin, Leptin, and Fatty Acids in the Maintenance of Metabolic Homeostasis through Adipose Tissue Crosstalk. Cell Metab. 2016;23:770-784. doi:10.1016/j.cmet.2016.04.011

21. Friedman JM. Leptin and the endocrine control of energy balance. Nat Metab. 2019;1:754-764. doi:10.1038/s42255-019-0095-y

22. Frühbeck G, Catalán V, Rodríguez A, Gómez-Ambrosi J. Adiponectin-leptin ratio: A promising index to estimate adipose tissue dysfunction. Relation with obesity-associated cardiometabolic risk.

Loading [MathJax]/jax/output/CommonHTML/jax.js 21623945.2017.1402151.

Page 16/31 
23. Amato MC, Giordano C, Galia M, Criscimanna A, Vitabile S, Midiri M, Galluzzo A, and AlkaMeSy Study Group. Visceral Adiposity Index: a reliable indicator of visceral fat function associated with cardiometabolic risk. Diabetes Care. 2010;33:920-922. doi: 10.2337/dc09-1825

24. Amato MC, Giordano C. Visceral adiposity index: an indicator of adipose tissue dysfunction. Int J Endocrinol. 2014; 2014:730827. doi:10.1155/2014/730827

25. Oh S-K, Cho A-R, Kwon Y-J, Lee H-S, Lee J-W. Derivation and validation of a new visceral adiposity index for predicting visceral obesity and cardiometabolic risk in a Korean population. PLoS One. 2018;13:e0203787. doi: 10.1371/journal.pone.0203787

26. Xia MF, Chen Y, Lin HD, Ma H, Li XM, Aleteng Q, et al. A indicator of visceral adipose dysfunction to evaluate metabolic health in adult Chinese. Sci Rep 2016;6:38214. doi:10.1038/srep38214

27. Villarreal-Molina T, Posadas-Romero C, Romero-Hidalgo S, et al. The ABCA1 gene R230C variant is associated with decreased risk of premature coronary artery disease: the genetics of atherosclerotic disease (GEA) study. PLoS One. 2012;7:e49285. doi:10.1371/journal.pone.0049285

28. González-Salazar MC, Medina-Urrutia AX, Juárez-Rojas JG, Cardoso-Saldaña GC, Posadas-Sánchez R, Martínez-Alvarado R, Jorge-Galarza E, and Posadas-Romero C. Dietary patterns and physical activity in the mexican population: association with fatty liver. Gac Med Mex. 2014;150:39-47.

29. DeLong DM, DeLong ER, Wood PD, Lippel K, Rifkind BM. A comparison of methods for the estimation of plasma low-and very low-density lipoprotein cholesterol: The Lipid Research Clinics Prevalence Study. JAMA.1986;256:2372-2377.

30. Rodriguez-Ayala E, Gallegos-Cabrales EC, Gonzalez-Lopez L, et al. Towards precision medicine: defining and characterizing adipose tissue dysfunction to identify early immunometabolic risk in symptom-free adults from the GEMM family study. Adipocyte. 2020;9:153-169. doi:10.1080/21623945.2020.1743116

31. Colletti PM, Dustin LD, Wong ND, Shriki JE, Kawakubo M, Azen SP, Detrano RC. Does coronary calcium score predict future cardiac function? Association of subclinical atherosclerosis with left ventricular systolic and diastolic dysfunction at MR imaging in an elderly cohort. Radiology. 2010;257:64-70. doi:10.1148/radiol.10091868

32. McKimmie RL, Daniel KR, Carr JJ, Bowden DW, Freedman BI, Register TC, Hsu FC, Lohman KK, Weinberg RB, Wagenknecht LE. Hepatic steatosis and subclinical cardiovascular disease in a cohort enriched for type 2 diabetes: the diabetes heart study. Am J Gastroenterol. 2008;103:3029-35. doi:10.1111/j.1572-0241.2008.02188.x

33. American Diabetes Association. 2. Classification and Diagnosis of Diabetes. Diabetes Care. 2016;39:S13-S22. doi:10.2337/dc16-S005

34. 2017 ACC/AHA/AAPA/ABC/ACPM/AGS/APhA/ASH/ASPC/NMA/PCNA Guideline for the Prevention, Detection, Evaluation, and Management of High Blood Pressure in Adults: Executive Summary: A Report of the American College of Cardiology/American Heart Association Task Force on Clinical Practice Guidelines. Hypertension. 2018;71:1269-1324. doi:10.1161/HYP.0000000000000066 
35. Chachopoulos V, Dinas PC, Chasioti M, Jamurtas AZ, Koutedakis Y, Flouris AD. A Technique for Subcutaneous Abdominal Adipose Tissue Biopsy via a Non-diathermy Method. J Vis Exp. 2017;127:55593. doi:10.3791/55593

36. Miladinovic D, Cusick T, Mahon KL, et al. Assessment of Periprostatic and Subcutaneous Adipose Tissue Lipolysis and Adipocyte Size from Men with Localized Prostate Cancer. Cancers. 2020;12:1385. doi:10.3390/cancers12061385

37. Aguilar-Salinas CA, Olaiz G, Valles V, Torres JM, Gómez Pérez FJ, Rull JA, Rojas R, Franco A, Sepulveda J. High prevalence of low HDL cholesterol concentrations and mixed hyperlipidemia in a Mexican nationwide survey. J Lipid Res. 2001;42:1298-1307.

38. Ibrahim MM. Subcutaneous and visceral adipose tissue: structural and functional differences. Obes Rev. 2010;11:11-18. doi:10.1111/j.1467-789X.2009.00623.x

39. Strissel KJ, Stancheva Z, Miyoshi H, Perfield JW 2nd, DeFu-ria J, Jick Z, Greenberg AS, Obin MS. Adipocyte death, adipose tissue remodeling, and obesity complications. Diabetes. 2007;56:29102918. doi:10.2337/db07-0767

40. Landgraf K, Rockstroh D, Wagner IV, et al. Evidence of early alterations in adipose tissue biology and function and its association with obesity-related inflammation and insulin resistance in children. Diabetes. 2015;64:1249-1261. doi:10.2337/db14-0744

\section{Figures}




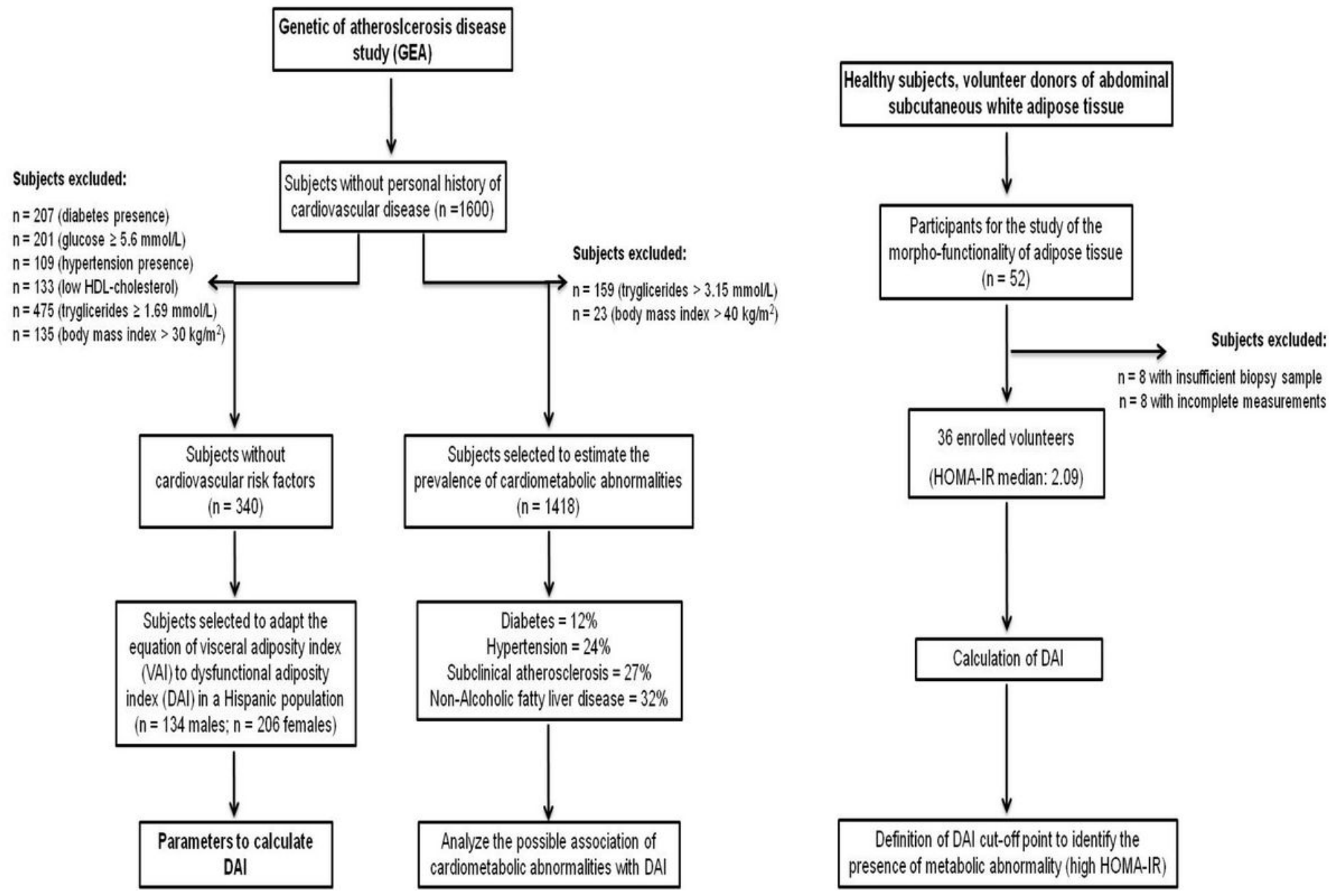

\section{Figure 1}

Study flowchart. 1a) GEA study. Diabetes defined as glucose $>7.0 \mathrm{mmol} / \mathrm{L}$, hypoglycemic treatment or previous diagnosis; hypertension as self-reported treatment with antihypertensive medications or systolic/diastolic blood pressure $\geq 140 / 90 \mathrm{mmHg}$; subclinical atherosclerosis as coronary artery calcium $>0$; non-alcoholic fatty liver disease as spleen-liver attenuation ratio < 1.0; and low HDL-cholesterol as values $<1.03 \mathrm{mmol} / \mathrm{L}$ or $<1.29 \mathrm{mmol} / \mathrm{L}$ for men or women; respectively. $1 \mathrm{~b}$ ) Study of the adipose tissue functionality. HOMA-IR: homeostatic model assessment of insulin resistance; HDL: high density lipoprotein. 


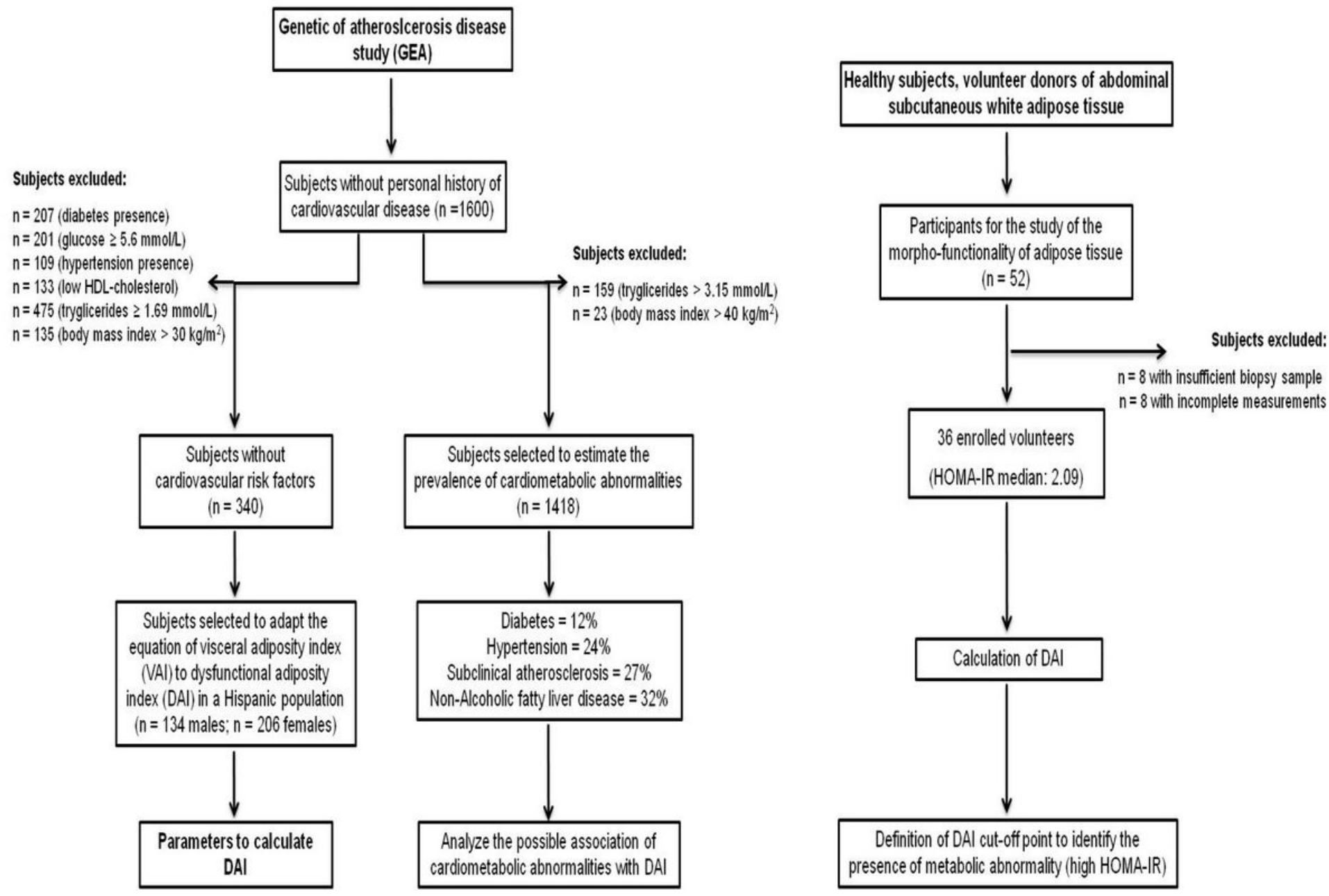

\section{Figure 1}

Study flowchart. 1a) GEA study. Diabetes defined as glucose $>7.0 \mathrm{mmol} / \mathrm{L}$, hypoglycemic treatment or previous diagnosis; hypertension as self-reported treatment with antihypertensive medications or systolic/diastolic blood pressure $\geq 140 / 90 \mathrm{mmHg}$; subclinical atherosclerosis as coronary artery calcium $>0$; non-alcoholic fatty liver disease as spleen-liver attenuation ratio < 1.0; and low HDL-cholesterol as values $<1.03 \mathrm{mmol} / \mathrm{L}$ or $<1.29 \mathrm{mmol} / \mathrm{L}$ for men or women; respectively. $1 \mathrm{~b}$ ) Study of the adipose tissue functionality. HOMA-IR: homeostatic model assessment of insulin resistance; HDL: high density lipoprotein. 
2a

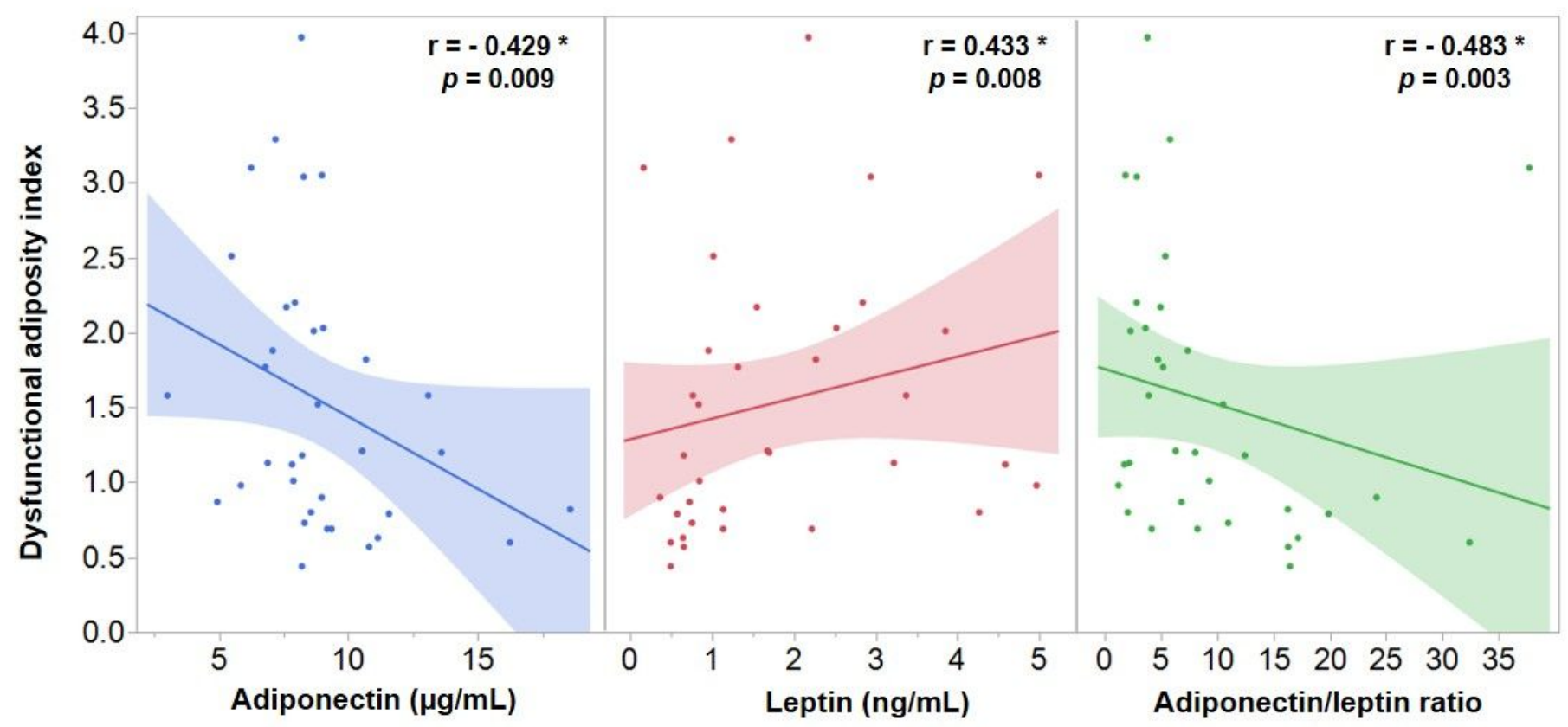

2b

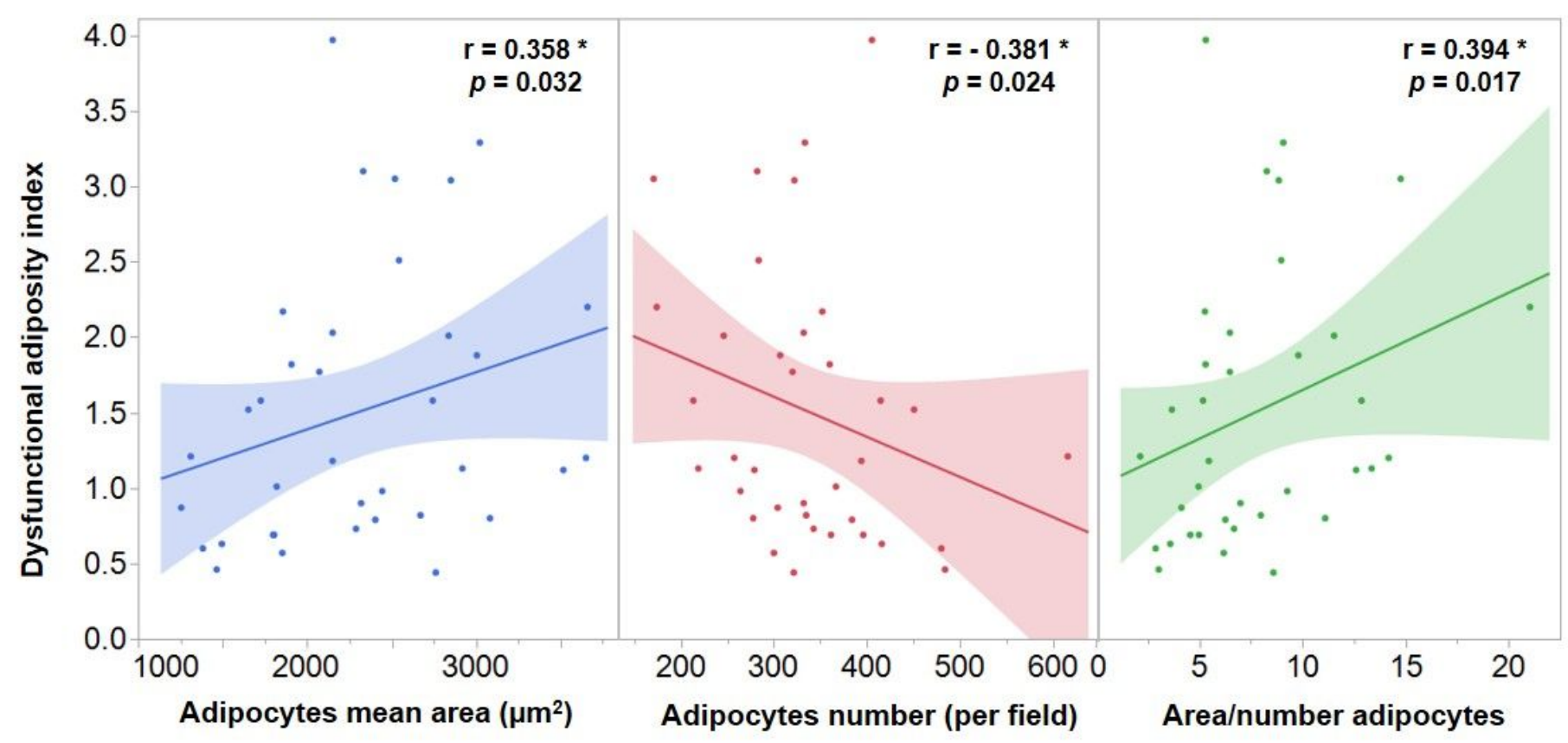

Figure 2

Correlation of DAl with functional (2a) and morphological (2b) characteristics of adipose tissue. The analysis include 36 healthy subjects. DAl: dysfunctional adipose index. * Spearman correlation coefficient, shaded area represents the $95 \%$ confidence interval. 
2a

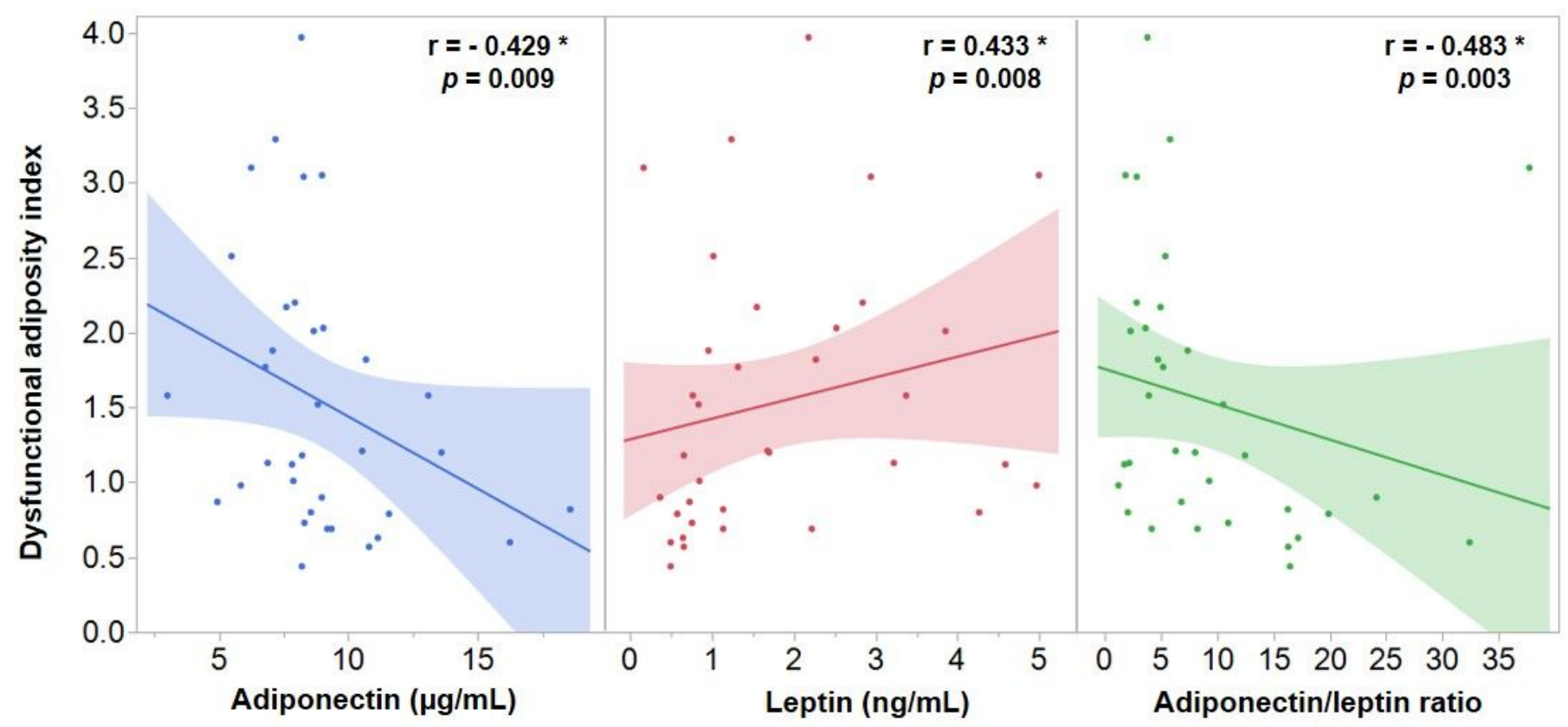

2b

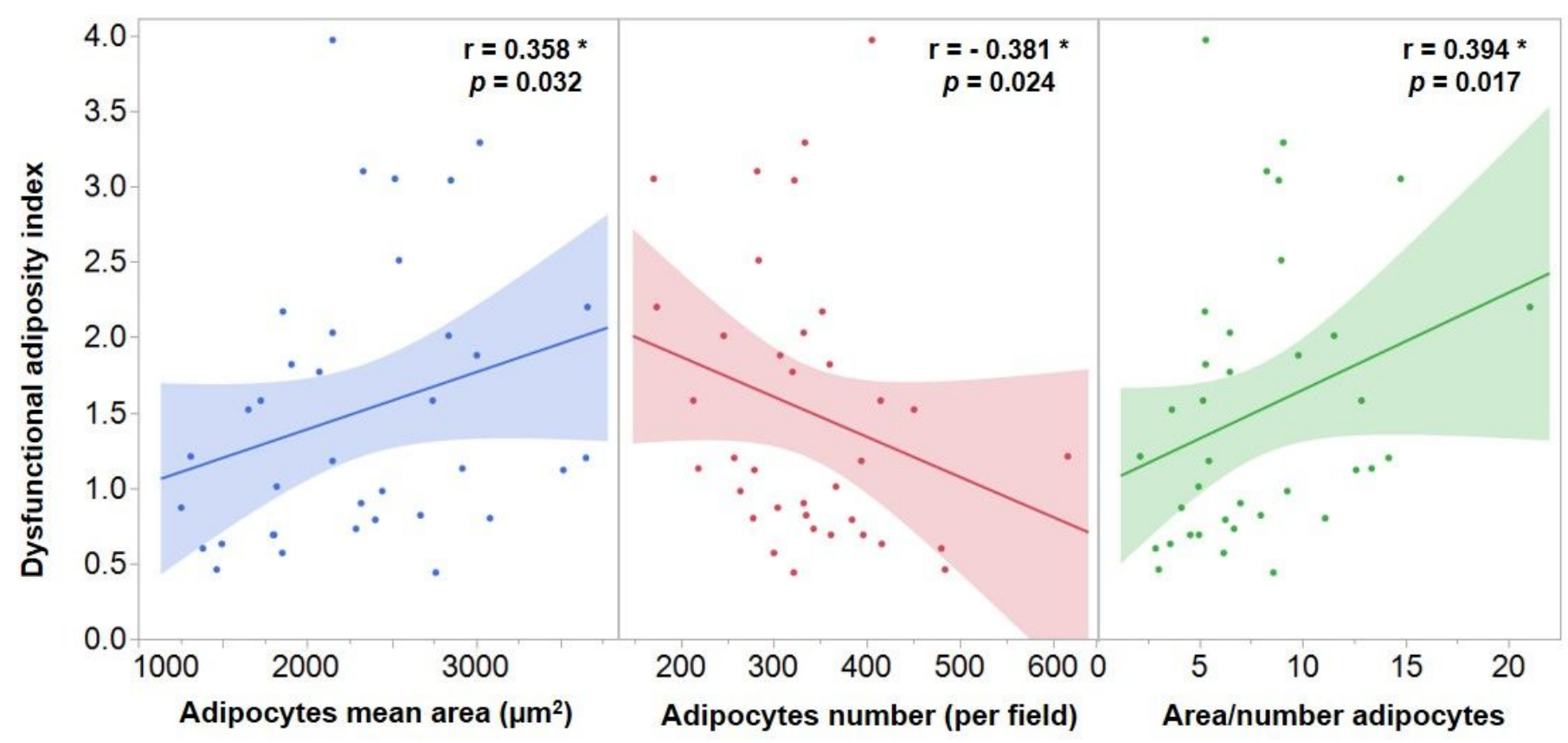

Figure 2

Correlation of DAl with functional (2a) and morphological (2b) characteristics of adipose tissue. The analysis include 36 healthy subjects. DAl: dysfunctional adipose index. * Spearman correlation coefficient, shaded area represents the $95 \%$ confidence interval. 


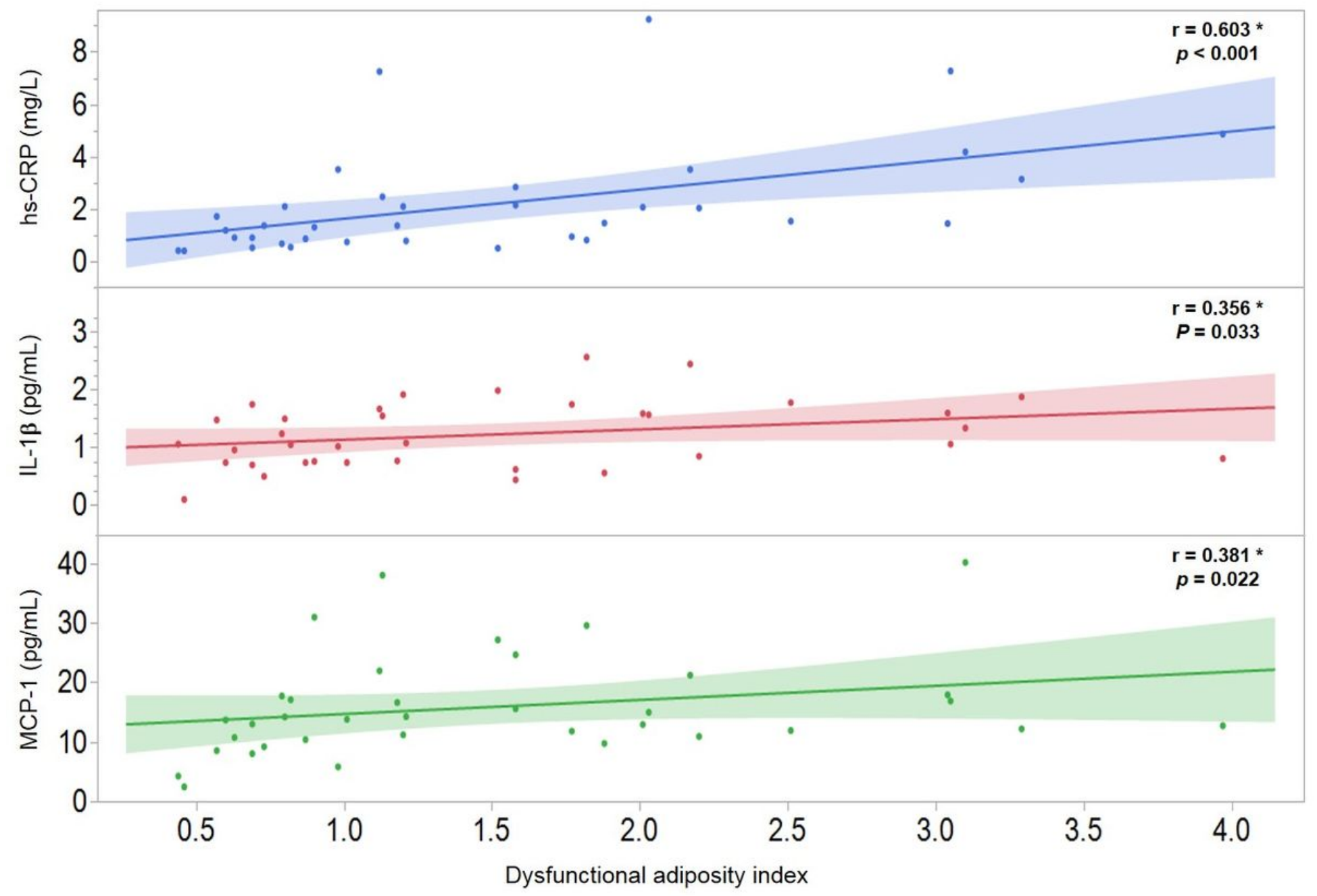

Figure 3

Correlation of dysfunctional adiposity index with systematic inflammation markers in 36 healthy subjects. hs-CRP: high-sensitivity C-reactive protein; IL: interleukin; MCP-1: monocyte chemoatractant protein-1. * Spearman correlation coefficient, shaded area represents the $95 \%$ confidence interval. 


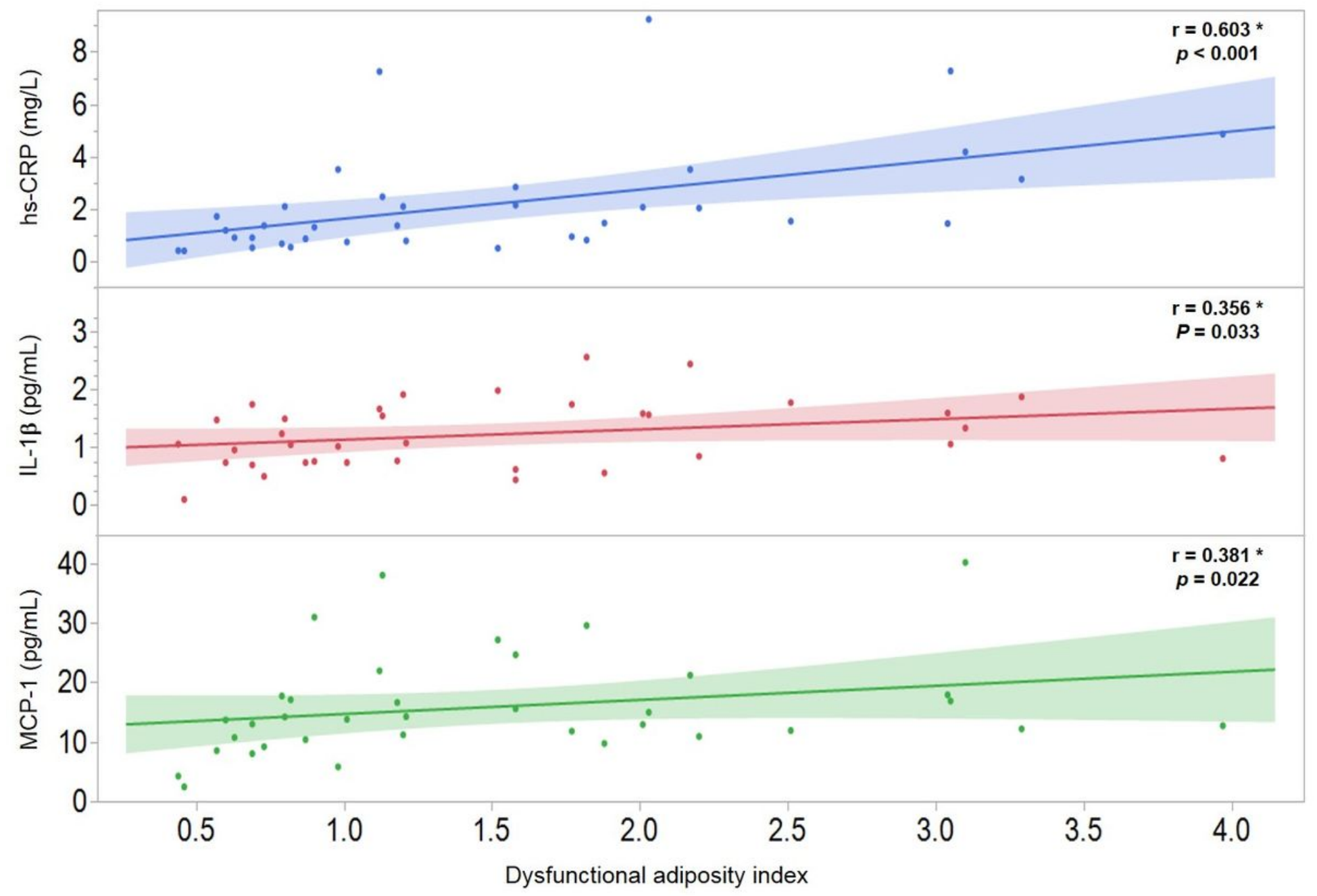

Figure 3

Correlation of dysfunctional adiposity index with systematic inflammation markers in 36 healthy subjects. hs-CRP: high-sensitivity C-reactive protein; IL: interleukin; MCP-1: monocyte chemoatractant protein-1. * Spearman correlation coefficient, shaded area represents the $95 \%$ confidence interval. 


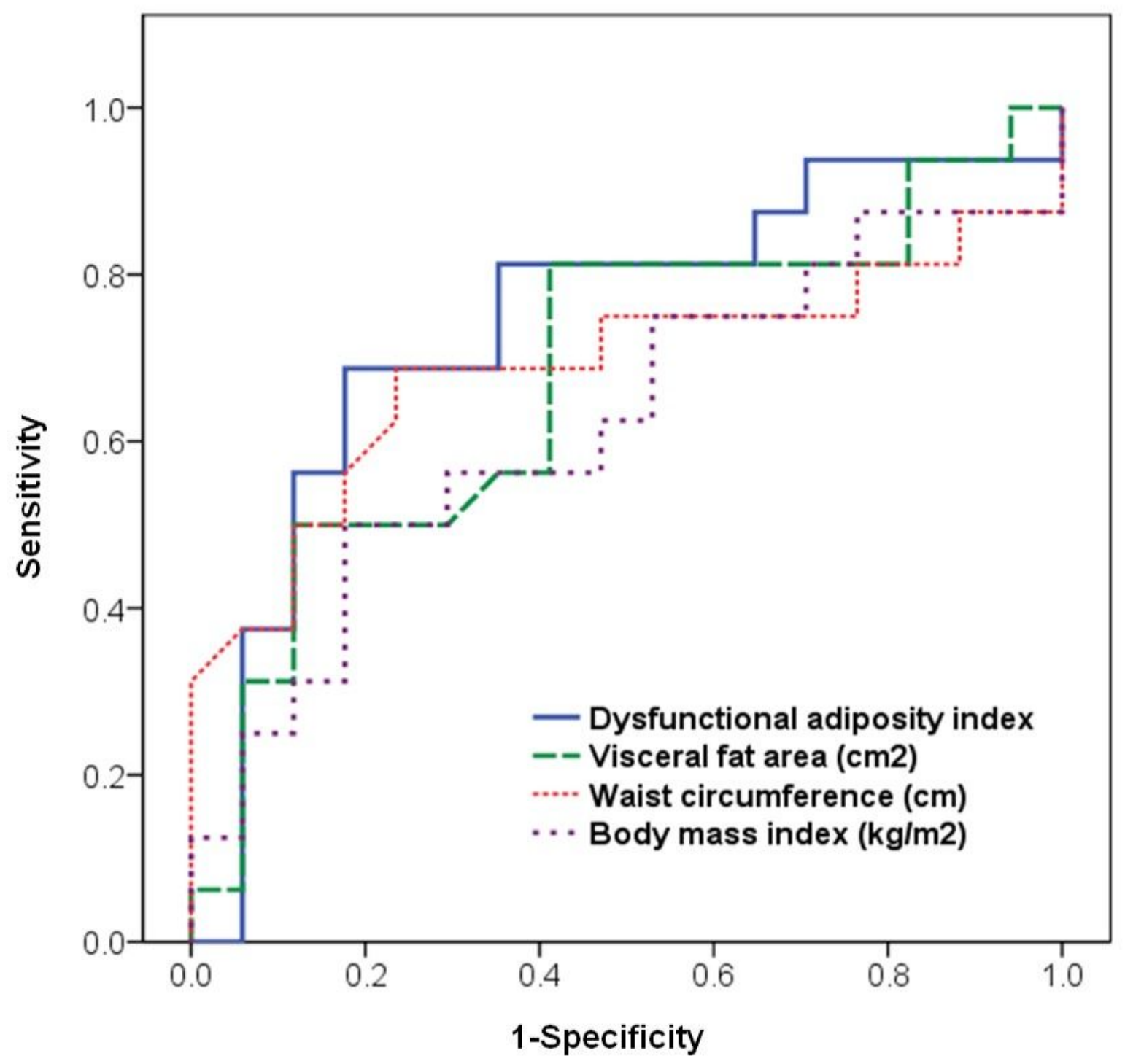

\begin{tabular}{lcccc}
\hline \multicolumn{5}{c}{ ROC Curves for HOMA-IR $\geq 2.09^{*}$} \\
\hline \multicolumn{1}{c}{ Adiposity parameters } & AUC & SE & $95 \% \mathrm{Cl}$ & $p$ \\
\hline Dysfunctional adiposity index & $\mathbf{0 . 7 4 3}$ & $\mathbf{0 . 0 9 1}$ & $\mathbf{0 . 5 6 4}$ to 0.922 & $\mathbf{0 . 0 1 7}$ \\
Visceral fat area $\left(\mathrm{cm}^{2}\right)$ & 0.678 & 0.096 & 0.489 to 0.867 & 0.081 \\
Waist circumference $(\mathrm{cm})$ & 0.688 & 0.100 & 0.494 to 0.884 & 0.066 \\
Body mass index $\left(\mathrm{kg} / \mathrm{m}^{2}\right)$ & 0.621 & 0.101 & 0.424 to 0.819 & 0.235 \\
\hline
\end{tabular}

Figure 4

Receiver operative characteristic curves to predict HOMA-IR $\geq 2.09$. HOMA-IR: homeostatic model assessment of insulin resistance; AUC: area under the curve; SE: standard error; Cl: confidence interval. * This represents the median value in 36 healthy subjects. 


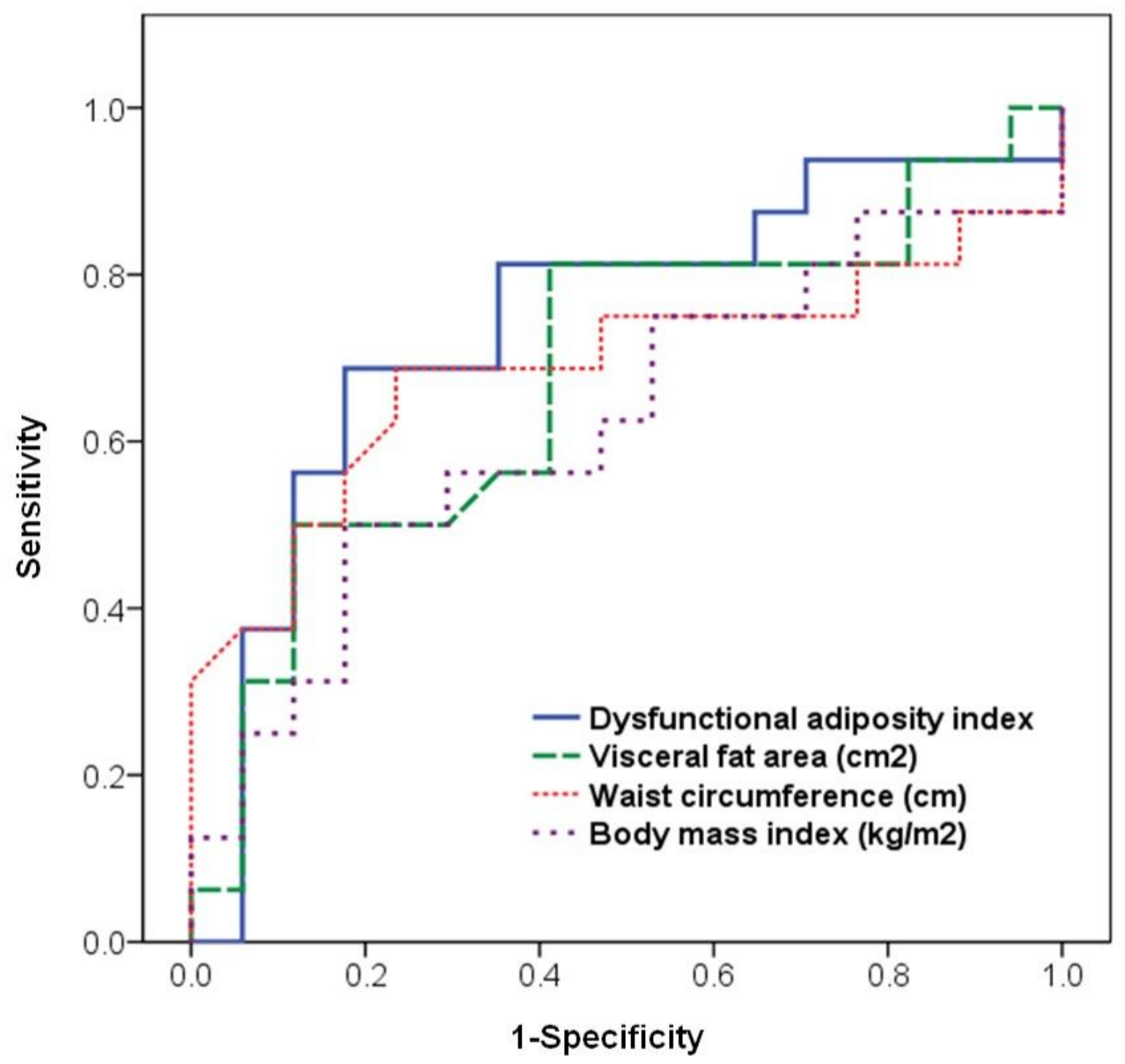

\begin{tabular}{lcccc}
\hline \multicolumn{5}{c}{ ROC Curves for HOMA-IR $\geq 2.09^{*}$} \\
\hline \multicolumn{1}{c}{ Adiposity parameters } & AUC & SE & $95 \% \mathrm{Cl}$ & $p$ \\
\hline Dysfunctional adiposity index & $\mathbf{0 . 7 4 3}$ & $\mathbf{0 . 0 9 1}$ & $\mathbf{0 . 5 6 4}$ to 0.922 & $\mathbf{0 . 0 1 7}$ \\
Visceral fat area $\left(\mathrm{cm}^{2}\right)$ & 0.678 & 0.096 & 0.489 to 0.867 & 0.081 \\
Waist circumference $(\mathrm{cm})$ & 0.688 & 0.100 & 0.494 to 0.884 & 0.066 \\
Body mass index $\left(\mathrm{kg} / \mathrm{m}^{2}\right)$ & 0.621 & 0.101 & 0.424 to 0.819 & 0.235 \\
\hline
\end{tabular}

Figure 4

Receiver operative characteristic curves to predict HOMA-IR $\geq 2.09$. HOMA-IR: homeostatic model assessment of insulin resistance; AUC: area under the curve; SE: standard error; Cl: confidence interval. * This represents the median value in 36 healthy subjects. 


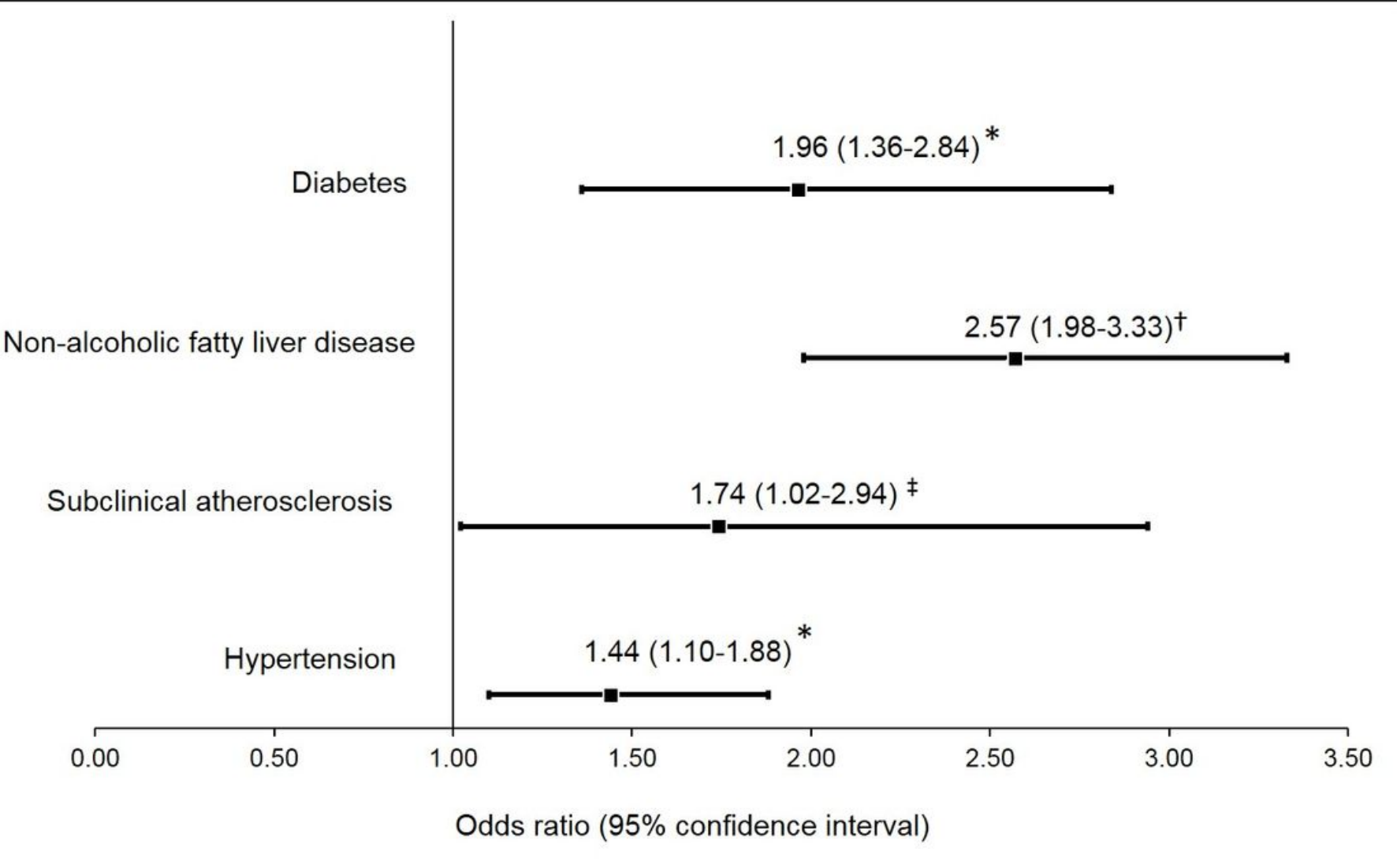

\section{Figure 5}

Association of high DAl (>1.065) with cardiometabolic abnormalities in 1418 subjects without cardiovascular disease. Diabetes defined as glucose $>7.0 \mathrm{mmol} / \mathrm{L}$, hypoglycemic treatment or previous diagnosis; non-alcoholic fatty liver disease as spleen-liver attenuation ratio $<1.0$; subclinical atherosclerosis as coronary artery calcium $>0$, and hypertension as self-reported treatment with antihypertensive medications or systolic/diastolic blood pressure $\geq 140 / 90 \mathrm{mmHg}$. DAl: dysfunctional adipose index. * Multiple logistic regression analysis adjusted by age, sex, and tobacco use. 


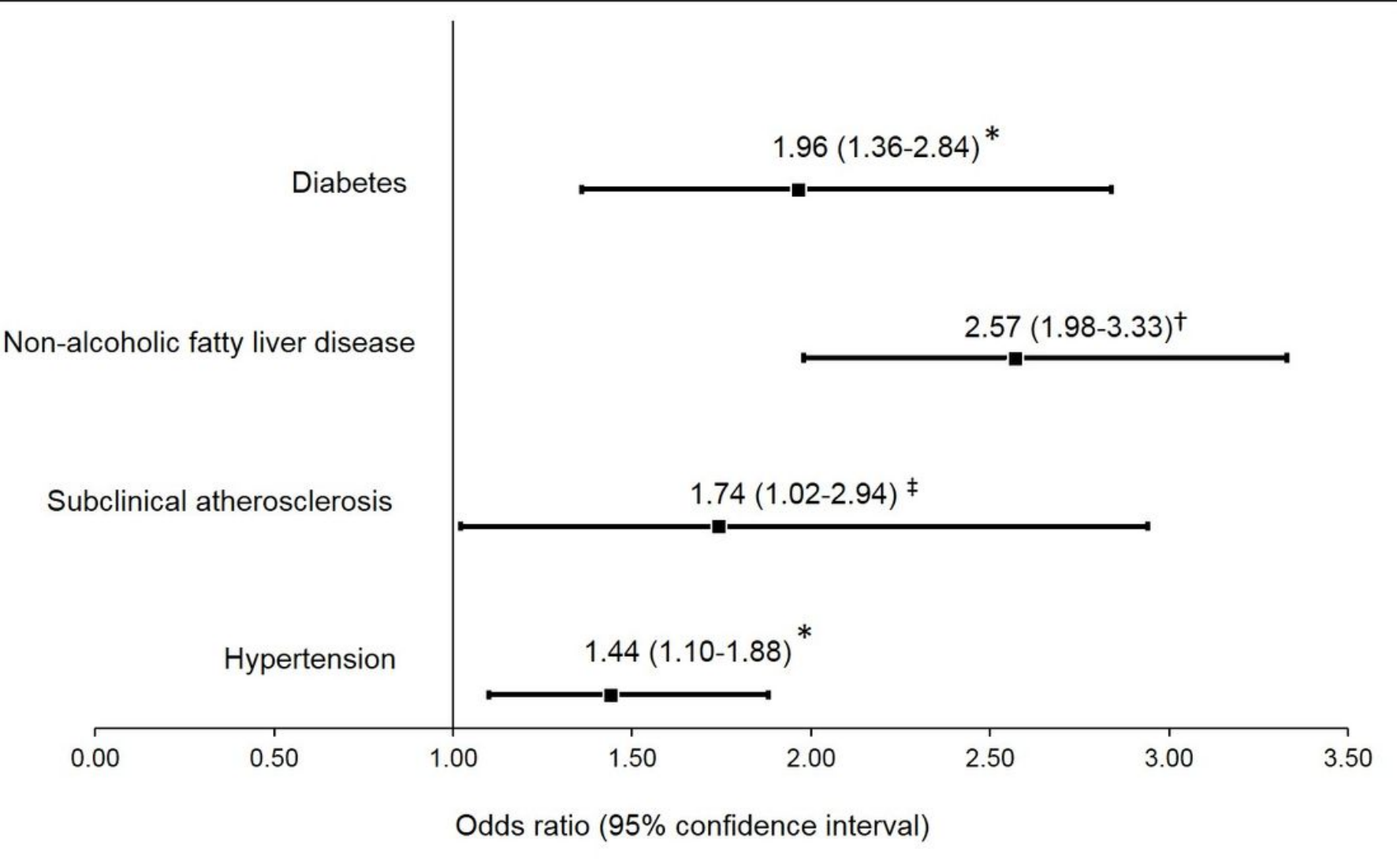

\section{Figure 5}

Association of high DAl (>1.065) with cardiometabolic abnormalities in 1418 subjects without cardiovascular disease. Diabetes defined as glucose $>7.0 \mathrm{mmol} / \mathrm{L}$, hypoglycemic treatment or previous diagnosis; non-alcoholic fatty liver disease as spleen-liver attenuation ratio $<1.0$; subclinical atherosclerosis as coronary artery calcium $>0$, and hypertension as self-reported treatment with antihypertensive medications or systolic/diastolic blood pressure $\geq 140 / 90 \mathrm{mmHg}$. DAl: dysfunctional adipose index. * Multiple logistic regression analysis adjusted by age, sex, and tobacco use. 


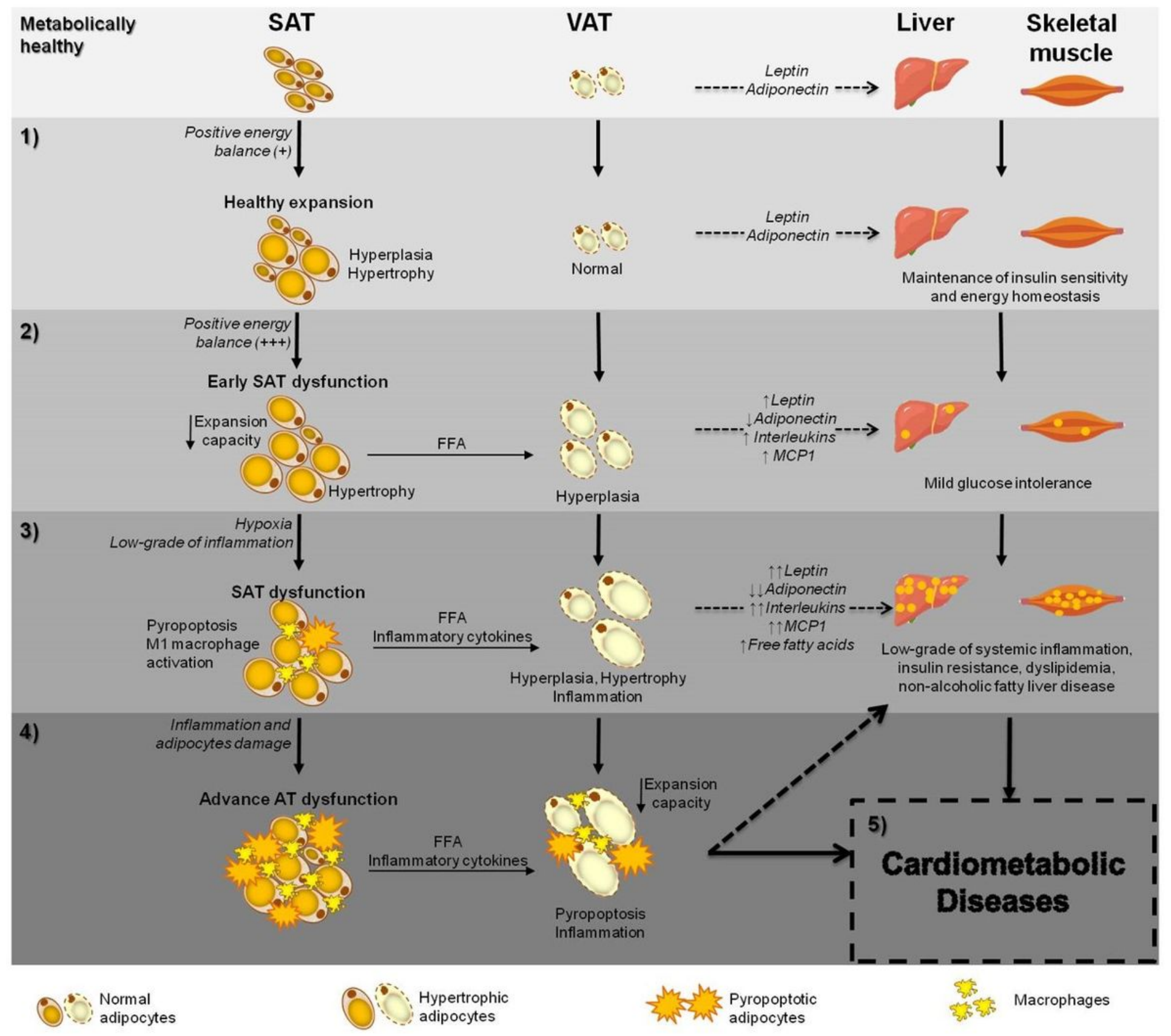

\section{Figure 6}

Hypothesis of the progression of adipose tissue dysfunction. 1) overnutrition and reduced physical activity lead to positive energy balance which promotes subcutaneous adipose tissue (SAT) expansion through hyperplasia and hypertrophy buffering energy excess and maintaining metabolic homeostasis; 2) maintenance of a positive energy balance reduces SAT adipogenic potential limiting SAT expansion, This early phase of adipose tissue dysfunction is characterized by a reduction in adiponectin synthesis and secretion from subcutaneous adipocytes and an increase in leptin and other inflammatory molecules (i.e. MCP-1: monocyte chemoattractant protein-1, ILs: interleukins 1区 or 6 that stimulates hepatic high sensitivity C-reactive protein synthesis) secretion; 3 ) dysfunctional subcutaneous adipocytes become unable to store energy surplus, increasing efflux of free fatty acids (FFA). These hypertrophic adipocytes 
inflammatory M1 macrophages stimulating local low-grade inflammation. In this phase, SAT-derived FFAs are efficiently stored in visceral adipocytes, leading to visceral adipose tissue (VAT) expansion; 4) in a more advanced stage, enlarged visceral adipocytes also develop hypoxia, pyropoptosis and become dysfunctional. In this stage, both subcutaneous and visceral adipose tissues increase the release of inflammatory molecules as well as FFA, leading to lipid deposition in cardiomyocytes, skeletal myocytes, hepatocytes, pancreatic beta cells and vascular endothelial cells among others. Lipid accumulation in non-adipose tissue induces lipotoxicity and oxidative stress and the development of glucose intolerance, insulin resistance, non-alcoholic fatty liver disease and dyslipidemia; 5) in the advanced stages of adipose tissue dysfunction, increased lipotoxicity, glucotoxicity, systemic inflammation and oxidative stress induces severe damage to the liver, skeletal muscle, pancreatic islets, vasculature and other tissues, leading to irreversible cardiometabolic diseases.

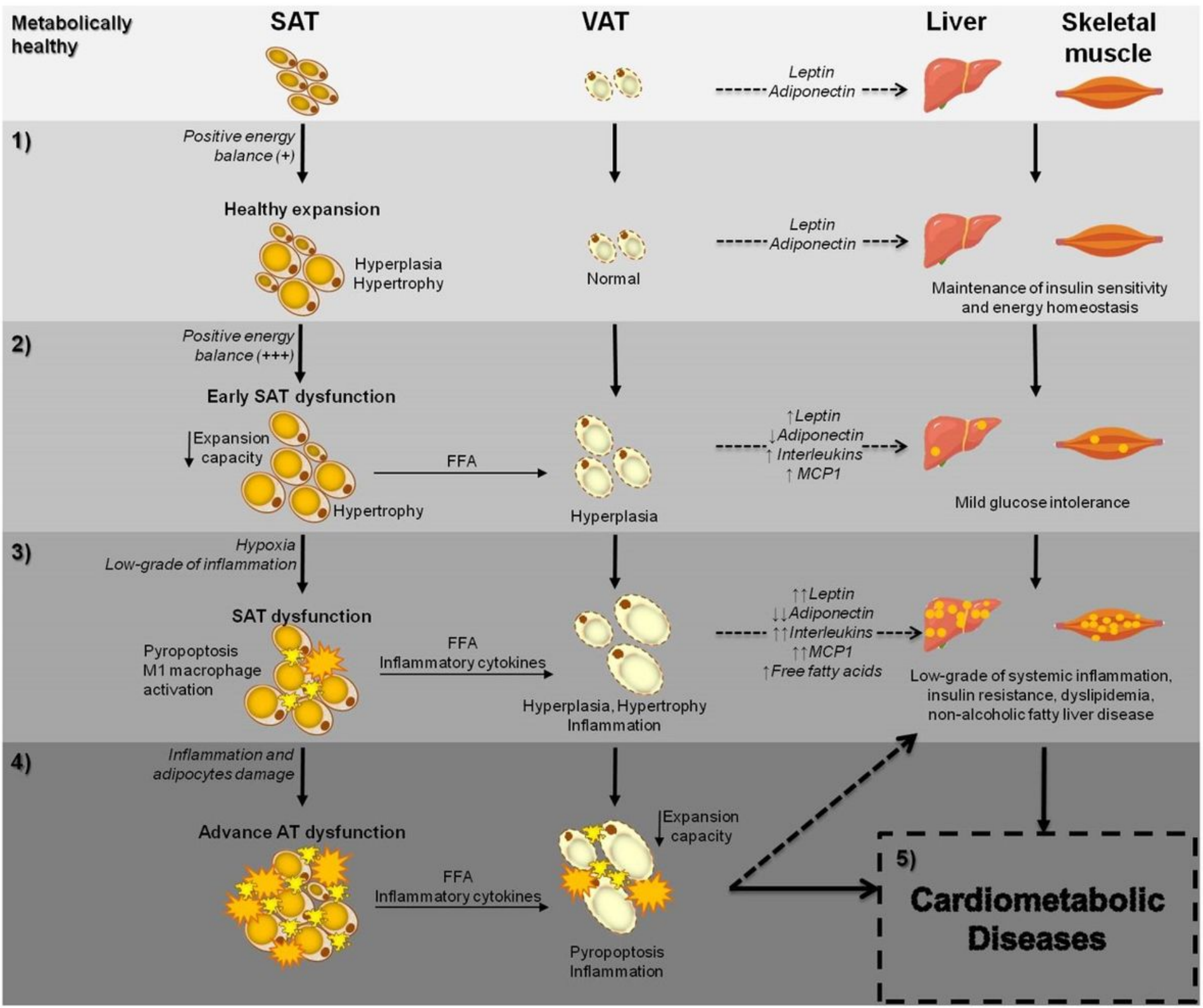


Hypothesis of the progression of adipose tissue dysfunction. 1) overnutrition and reduced physical activity lead to positive energy balance which promotes subcutaneous adipose tissue (SAT) expansion through hyperplasia and hypertrophy buffering energy excess and maintaining metabolic homeostasis; 2) maintenance of a positive energy balance reduces SAT adipogenic potential limiting SAT expansion, This early phase of adipose tissue dysfunction is characterized by a reduction in adiponectin synthesis and secretion from subcutaneous adipocytes and an increase in leptin and other inflammatory molecules (i.e. MCP-1: monocyte chemoattractant protein-1, ILs: interleukins 1区 or 6 that stimulates hepatic high sensitivity C-reactive protein synthesis) secretion; 3 ) dysfunctional subcutaneous adipocytes become unable to store energy surplus, increasing efflux of free fatty acids (FFA). These hypertrophic adipocytes are also prone to hypoxia and pyropoptosis, releasing damage-associated molecular patterns that recruit inflammatory M1 macrophages stimulating local low-grade inflammation. In this phase, SAT-derived FFAs are efficiently stored in visceral adipocytes, leading to visceral adipose tissue (VAT) expansion; 4) in a more advanced stage, enlarged visceral adipocytes also develop hypoxia, pyropoptosis and become dysfunctional. In this stage, both subcutaneous and visceral adipose tissues increase the release of inflammatory molecules as well as FFA, leading to lipid deposition in cardiomyocytes, skeletal myocytes, hepatocytes, pancreatic beta cells and vascular endothelial cells among others. Lipid accumulation in non-adipose tissue induces lipotoxicity and oxidative stress and the development of glucose intolerance, insulin resistance, non-alcoholic fatty liver disease and dyslipidemia; 5) in the advanced stages of adipose tissue dysfunction, increased lipotoxicity, glucotoxicity, systemic inflammation and oxidative stress induces severe damage to the liver, skeletal muscle, pancreatic islets, vasculature and other tissues, leading to irreversible cardiometabolic diseases.

\section{Supplementary Files}

This is a list of supplementary files associated with this preprint. Click to download.

- Additionalfile1..docx

- Additionalfile1..docx 